OPEN ACCESS

Edited by: Morgan Craig,

University of Montreal, Canada

Reviewed by:

Yanguang Cao,

University of North Carolina at Chape Hill, United States

Patrick Glassman,

University of Pennsylvania,

United States

${ }^{*}$ Correspondence:

Georgi I. Kapitanov

georgi.kapitanov@pfizer.com

Specialty section: This article was submitted to Drug Discovery in Bioinformatics,

a section of the journal

Frontiers in Bioinformatics

Received: 02 July 2021

Accepted: 23 August 2021 Published: 03 September 2021

Citation:

Kapitanov Gl, Chabot JR, Narula J,

Roy $M$, Neubert $H$, Palandra J, Farrokhi $V$, Johnson JS, Webster $R$ and Jones HM (2021) A Mechanistic

Site-Of-Action Model: A Tool for Informing Right Target, Right

Compound, And Right Dose for

Therapeutic Antagonistic

Antibody Programs.

Front. Bioinform. 1:731340.

doi: 10.3389/fbinf.2021.731340

\section{A Mechanistic Site-Of-Action Model: A Tool for Informing Right Target, Right Compound, And Right Dose for Therapeutic Antagonistic Antibody Programs}

\author{
Georgi I. Kapitanov ${ }^{1 *}$, Jeffrey R. Chabot ${ }^{1}$, Jatin Narula ${ }^{1}$, Mahua Roy ${ }^{1}$, Hendrik Neubert ${ }^{2}$, \\ Joe Palandra ${ }^{2}$, Vahid Farrokhi ${ }^{2}$, Jay S. Johnson ${ }^{2}$, Robert Webster ${ }^{1}$ and Hannah M. Jones ${ }^{1}$ \\ ${ }^{1}$ BioMedicine Design, Pfizer Worldwide R\&D, Cambridge, MA, United States, ${ }^{2}$ BioMedicine Design, Pfizer Worldwide R\&D, \\ Andover, MA, United States
}

Quantitative modeling is increasingly utilized in the drug discovery and development process, from the initial stages of target selection, through clinical studies. The modeling can provide guidance on three major questions-is this the right target, what are the right compound properties, and what is the right dose for moving the best possible candidate forward. In this manuscript, we present a site-of-action modeling framework which we apply to monoclonal antibodies against soluble targets. We give a comprehensive overview of how we construct the model and how we parametrize it and include several examples of how to apply this framework for answering the questions postulated above. The utilities and limitations of this approach are discussed.

Keywords: site of action, PKPD, QSP, modeling and simulation, LC-MS

\section{INTRODUCTION}

Modeling and simulation tools have become an essential part of the drug development process (Norris et al., 2000; Lalonde et al., 2007; Barrett et al., 2008; Edginton et al., 2008; Mager and Jusko, 2008; Rajman, 2008; Jones et al., 2009; Allerheiligen, 2010; van der Graaf and Benson, 2011; Zhao et al., 2011; Jones et al., 2012a; Knight-Schrijver et al., 2016; Danhof et al., 2018; Nijsen et al., 2018). Applying quantitative analyses early in the drug discovery can be very informative for selecting and de-selecting those programs with the best/least chance of clinical success. Traditional pharmacokinetics/pharmacodynamics (PKPD) models, while still widely utilized (Meibohm and Derendorf, 1997; Derendorf and Meibohm, 1999; Rajman, 2008), have gradually given place to increased mechanistic modeling complexity, with the intent to achieve higher predictive accuracy and mechanistic insights. These mechanistic modeling techniques include systems biology (SB) (Kitano, 2005; Kohl et al., 2010; Benson et al., 2011), quantitative systems pharmacology (QSP) (Hopkins, 2008; Allerheiligen, 2010; van der Graaf and Benson, 2011; van der Graaf, 2012; Jusko, 2013; Rogers et al., 2013; Peterson and Riggs, 2015; Knight-Schrijver et al., 2016; Danhof et al., 2018; Nijsen et al., 2018; Cucurull-Sanchez et al., 2019), and physiologically based pharmacokinetics (PBPK) (Baxter et al., 1994; Andersen, 1995; Baxter et al., 1995; Hoang, 1995; Arundel, 1997; Blakey et al., 1997; Nestorov et al., 1998; Grass and Sinko, 2002; Aarons, 2005; Jones et al., 2006a; Jones et al., 2006b; Cai et al., 2006; Barton et al., 2007; Nestorov, 2007; Edginton et al., 2008; Loizou et al., 2008; Jones et al., 2009; Chabot et al., 2011; Jones et al., 2011; Jones et al., 2012a; Jones et al., 2012b; Bouzom 
et al., 2012; Huang and Rowland, 2012; Rostami-Hodjegan et al., 2012; Shah and Betts, 2012; Zhao et al., 2012; Jones et al., 2013). Traditional empirical PKPD models are useful in predicting dosing and estimating pharmacology/efficacy in later stage clinical development and translation from pre-clinical animal models to humans. However, an extensive amount of pre-clinical PKPD data is needed to utilize them which limits their ability to be used to make early pre-clinical recommendations, before lead candidates are defined. In contrast, the mechanistic models, while often complex and computationally intensive, appear more suitable for overall disease and molecule modality recommendations.

Early stage biologics drug discovery programs concern themselves with three main questions: (1) is the proposed target biologically relevant and is hitting the target feasible; (2) what are the drug characteristics that would allow for biomarker modulation or efficacy; (3) what is the efficacious dose in humans? These three questions can be summarized as three components to each project: right target, right compound, right dose. Considering the high number of potential new targets, a flexible mechanistic modeling framework is needed that can be used to perform sensitivity analysis on a discrete number of parameters. This approach would quickly pinpoint gaps in knowledge that can be tested experimentally and make timely recommendations for each of the three components of project development. Therefore, for this purpose, one needs a model that is on the spectrum of complexity somewhere between the traditional PKPD and the multiscale systems biology models. We propose a site-ofaction (SoA) model for assisting in the discovery and development of biologics.

The site-of-action model extends a two compartment PKPD model by including the mechanistic interactions of the drug and its target (e.g., binding, unbinding and drug-target complex clearance), the relevant properties of the target, as well as a separate compartment that models the tissues in which the disease progresses (a so-called site of action) (Brodfuehrer et al., 2014). Such a model can be implemented rapidly since it captures only the relevant biology and is expressed through a discrete number of differential equations, variables, and parameters, which allows for extensive sensitivity analysis to identify the important parameters and biological assumptions that need to be investigated further. Hence, this model should be considered a starting point from which to build out specific models of the biology of different targets, its main utility being in early stage projects.

A previous iteration of the model has been described by Tiwari et al. 2016a and used for assessing sensitivity of the projected target neutralization to target concentrations (Tiwari et al., 2016a) and antibody affinity (Tiwari, et al, 2017). The current iteration makes minor changes to the old model structure and goes into more detail in explaining the reasons for certain modeling and parameter value choices. We have implemented this approach successfully since, and, beyond the theoretical treatment in Tiwari et al. 2016a, in Applications of
SoA Model Methodology of this manuscript will be demonstrating its utility by several real-world examples. The modeling work is highly dependent on robust assays to inform the parametrization of the model (biomeasures), which is yet another important expansion to the work presented in Tiwari et al. 2016a. We have listed the typical assays and input data used in the Target Parameters section. For the purposes of this article, we will focus on soluble targets. Membrane targets deserve to be covered in a separate manuscript, both in terms of the modeling approach, as well as in terms of utilizing the range of biomeasure assays and tools for supporting the modeling efforts.

\section{MODEL STRUCTURE AND METHODS OF PARAMETRIZATION}

The model is an extension of a drug-target mechanistic binding two-compartment model that accounts for the relevant disease tissue, which is referred to as site of action (SoA). Free plasma drug (with concentration $D_{P}$ in plasma volume $V_{P}$ ) distributes into non-specific (peripheral with volume $V_{T}$ ) and SoA (disease-specific with volume $V_{S}$ ) compartments. In plasma and at the SoA, the drug binds reversibly to target protein (with concentrations $T_{P}$ and $T_{S}$, respectively) to form a drugtarget complex (with concentrations $C_{P}$ and $C_{S}$, respectively). The binding kinetics are characterized by a second-order association $\left(k_{o n}\right)$ and first-order dissociation $\left(k_{o f f}\right)$ rate constants. The model assumes target synthesis and degradation both in the central and the SoA compartments (expressed by the zero order rates $k s y n_{S}$, and $k s y n_{P}$ and first order rates $k_{d e g T p}$ and $k_{d e g T s}$, respectively), target distribution between plasma and the SoA $\left(k_{p s T}\right.$ and $\left.k_{s p T}\right)$, and drug - target complex distribution between plasma and SoA $\left(k_{p s C}\right.$ and $\left.k_{s p C}\right)$ and elimination in plasma only $\left(k_{e l C}\right)$. The modeling equations are:

$$
\begin{gathered}
\frac{d D_{P}}{d t}=A+k_{s p} D_{S} \frac{V_{S}}{V_{P}}+k_{t p} D_{T} \frac{V_{T}}{V_{P}}-k_{p s} D_{P}-k_{p t} D_{P} \\
+k_{o f f} C_{P}-k_{o n} D_{P} T_{P}-k_{e l} D_{P} \\
\frac{d D_{S}}{d t}=k_{p s} D_{P} \frac{V_{P}}{V_{S}}-k_{s p} D_{S}+k_{o f f} C_{S}-k_{o n} D_{S} T_{S} \\
\frac{d D_{T}}{d t}=k_{p t} D_{P} \frac{V_{P}}{V_{T}}-k_{t p} D_{T} \\
\frac{d t}{d t}=k_{s p C} C_{S} \frac{V_{S}}{V_{P}}-k_{p s C} C_{P}+k_{o n} D_{P} T_{P}-k_{o f f} C_{P}-k_{e l C} C_{P} \\
\frac{d C_{S}}{d t}=k_{p s C} C_{P} \frac{V_{P}}{V_{S}}-k_{s p C} C_{S}+k_{o n} D_{S} T_{S}-k_{o f f} C_{S} \\
\frac{d T_{P}}{d t}=k_{s p T} T_{S} \frac{V_{S}}{V_{P}}-k_{p s T} T_{P}+k_{o f f} C_{P}-k_{o n} D_{P} T_{P}+k_{s y n P}-k_{d e g T p} T_{P}
\end{gathered}
$$




$$
\frac{d T_{S}}{d t}=k_{p s T} T_{P} \frac{V_{P}}{V_{S}}-k_{s p T} T_{S}+k_{o f f} C_{S}-k_{o n} D_{S} T_{S}+k_{s y n S}-k_{d e g T s} T_{P}
$$

where $D_{i}, C_{i}$ and $T_{i}$ represent the concentrations of free drug, drug-target complex, and free target in plasma $(i=P)$, or SoA $(i=S)$ compartment, respectively. $D_{T}$ is the free drug concentration in the peripheral tissue compartment. $A$ is the drug influx function, which is administration dependent.

A schematic of the modeling reactions is shown in Figure 1. Table 1 lists the variables and parameters contained in the system of differential equations, with explanations.

The initial conditions of the variables above appear with a 0 after the subscript: $D_{P 0}$ is initial drug concentration in the plasma, $T_{S 0}$ is initial target concentration at the SoA, etc.

Table 2 presents the value of $A$ and initial conditions related to the drug variables dependent on administration route. Other administration routes can be incorporated as well.

\section{PARAMETER DETERMINATION}

The next few sections will discuss how the different parameters are estimated and suggest typical assumptions for their values. Initial parametrization of the model may be obtained from the literature or data repositories. However, when such information is unavailable, experimental determination of key model parameters may be required. Some of the experimental methods discussed here may not be applicable, appropriate, or even possible for particular targets. A conversation among modelers, biologists, and biomeasure analysts would determine the most appropriate path to appropriate parametrization of the model.

\section{Drug Distribution Parameters}

Monoclonal antibody (mAb) PK typically shows biphasic behavior and such data can be modeled using twocompartmental models, resulting in the estimation of $4 \mathrm{PK}$ parameters (e.g., V1, Cl, Q and V2) (Betts et al., 2018). A question then arises-what is the concentration of antibody at the SoA? There have been several preclinical studies that have been performed to measure concentrations in tissues relative to blood across different antibodies (Vugmeyster et al., 2008; Vugmeyster et al., 2010; Shah and Betts, 2013; Li et al., 2017; An et al., 2020). Antibodies distribute predominantly in the interstitium of tissues (Janeway and Walport, 2001), therefore the concentration ratio needs to be adjusted for the interstitial volume of the tissue of interest. Generally, the volume of the interstitium is around $1 / 3$ of the total tissue volume (Poulin and Theil, 2002) (which includes peripheral blood and cells), unless one deals with certain specific organs like muscles or the brain (Shah and Betts, 2013). The ratio of total tissue to serum concentration for most organs in preclinical species is around 10\% (Shah and Betts, 2013; Vugmeyster et al., 2010). Therefore, our recommendation is to use $30 \%(=10 \% / 1 / 3)$ as a standard ratio parameter for non-brain and non-muscle tissue SoAs.

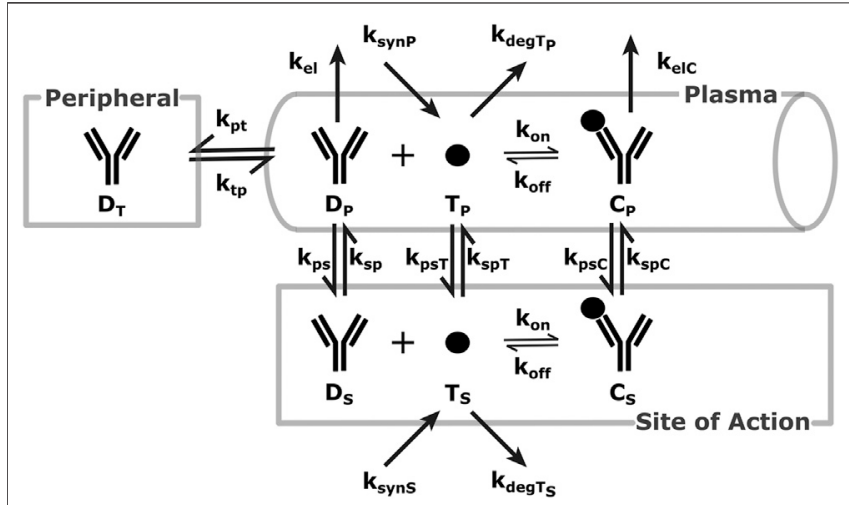

FIGURE 1 | SoA Model Scheme: A diagram describing the distribution and elimination of the mAb (denoted by $\mathrm{D}$ ), synthesis, distribution and elimination of the target (denoted by $T$ ) and the interactions between the mAb and target and the distribution and elimination of the resulting $\mathrm{mAb}$ : target complex (denoted by C). Subscripts describe the compartments - $p$ for plasma, $t$ for peripheral tissues, $s$ for the site of action. Detailed descriptions of all variables and parameters are in Model Structure and Methods of Parametrization and Table 1.

The following method can account for any ratio deemed appropriate for the particular project.

The calculations for the drug distribution constants presented here have two simultaneous aims: to retain mAb plasma $\mathrm{PK}$ and maintain the average concentration ratio (expressed as the parameter ratio) between the SoA and the plasma compartments (ratio of areas under the curve (AUCs) is equivalent). The following relationships are derived based on steady state analysis of total $\mathrm{mAb}$ concentration pharmacokinetics:

$$
\begin{gathered}
k_{p s}=\operatorname{ratio}_{s p} \frac{V_{S}}{V_{P}} \\
k_{p t}=\frac{Q}{V_{P}}-k_{p s} \\
V_{T}=\frac{V_{P} k_{p t}}{k_{t p}},
\end{gathered}
$$

where

$$
k_{s p}=k_{t p}=\frac{Q}{V_{2}} .
$$

There is an important distinction between $V_{2}$ and $V_{T}$ which warrants further elaboration. Fixing the ratio of average drug concentration at the SoA vs the plasma, while preserving plasma $\mathrm{PK}$, necessitates an extra degree of freedom in the calculations. Since drug concentrations in the peripheral tissue are rarely of interest, the peripheral tissue volume is a convenient (and mathematically sound) choice. However, the calculations of the drug distribution rates are done with the peripheral tissue volume of distribution from the PK parameter estimates, $V_{2}$ (see Table 1). In our practice, $V_{T}$ is not used and peripheral $\mathrm{mAb}$ concentrations not tracked (as opposed to SoA concentrations), but understanding of the mathematics behind the model would 
TABLE 1 | Definition of parameters used in SoA model.

\begin{tabular}{|c|c|c|c|}
\hline Parameter & Description & Value & Units \\
\hline$V_{P}$ & Central compartment volume (plasma) & Drug specific & $\mathrm{L}$ \\
\hline Q & Drug distributive clearance rate & Drug specific & L/day \\
\hline $\mathrm{Cl}$ & Drug elimination clearance rate & Drug specific & L/day \\
\hline$V_{S}$ & Volume of SoA interstitial space & Tissue specific & $\mathrm{L}$ \\
\hline$V_{T}$ & Peripheral tissue volume (calculated) & Model specific & $\mathrm{L}$ \\
\hline$V_{2}$ & Peripheral tissue volume (from two-compartment PK) & Drug specific & $\mathrm{L}$ \\
\hline$D_{0}$ & Dose & Study specific & Nanomole \\
\hline$k_{a}$ & Rate of absorption post subcutaneous drug administration & Drug specific & 1/day \\
\hline$F$ & Bioavailability post subcutaneous drug administration & Drug specific & Dimensionless \\
\hline$Q_{\text {target }}$ & Target distributive clearance rate & Target specific & L/day \\
\hline ratio & Ratio of plasma versus SoA drug concentrations at steady state & SoA specific & Dimensionless \\
\hline$k_{o n}$ & Drug-target concentration-dependent association rate & Drug specific & $\mathrm{nM}^{-1}$ day $^{-1}$ \\
\hline$k_{p s}$ & Rate constant of drug distribution from plasma to SoA & ratio $* \frac{Q}{V_{2}} * \frac{V_{S}}{V_{P}}$ & 1/day \\
\hline$k_{s p}$ & Rate constant of drug distribution from SoA to plasma & $\frac{Q}{V_{2}}$ & 1/day \\
\hline$k_{p t}$ & Rate constant of drug distribution from plasma to peripheral tissue & $\frac{Q}{V_{2}}-k_{p s}$ & 1/day \\
\hline$k_{t p}$ & Rate constant of drug distribution from peripheral tissue to plasma & $\frac{Q}{V_{2}}$ & 1/day \\
\hline$k_{p s T}$ & Rate constant of target distribution from plasma to SoA & $\frac{Q_{\text {target }}^{2}}{V_{P}}$ & 1/day \\
\hline$k_{s p T}$ & Rate constant of target distribution from SoA to plasma & Calculated to ensure target equilibrium in absence of drug & 1/day \\
\hline$k_{p s C}$ & Rate constant of complex distribution from plasma to SoA & $k_{p s}$ & 1/day \\
\hline$k_{s p C}$ & Rate constant of complex distribution from SoA to plasma & $k_{s p}$ & 1/day \\
\hline$k_{e l}$ & Rate constant of drug elimination from plasma & $\frac{C l}{V_{P}}$ & 1/day \\
\hline$k_{\text {degtp }}$ & Rate constant of target elimination from plasma & Target specific & 1/day \\
\hline$k_{\text {degTs }}$ & Rate constant of target elimination from SoA & Target specific & 1/day \\
\hline$k_{e l C}$ & Rate constant of complex elimination from plasma & For soluble target can be assumed $=k_{e l}$, unless data are avalable & 1/day \\
\hline$k_{\text {off }}$ & First-order dissociation rate constant of antibody & $k_{\text {on }} * K_{D}$ & 1/day \\
\hline$k_{\text {synP }}$ & Zero order target synthesis rate in plasma & Calculated to ensure target equilibrium in absence of drug & nM/day \\
\hline$k_{\text {syns }}$ & Zero order target synthesis rate in SoA & Calculated to ensure target equilibrium in absence of drug & $\mathrm{nM} /$ day \\
\hline
\end{tabular}

TABLE 2 | Expressions for $\boldsymbol{A}$ depending on route of drug administration.

\begin{tabular}{lcc} 
Route of administration & Expression for $\boldsymbol{A}$ & $\begin{array}{c}\text { Drug-related } \\
\text { initial conditions }\end{array}$ \\
\hline Intravenous bolus & $A=0$ & $D_{P O}=D_{0}, D_{T O}=D_{S O}=0$ \\
Subcutaneous & $A=D_{0} * F * k_{a}$ & $D_{P O}=D_{T O}=D_{S O}=0$
\end{tabular}

be incomplete without $V_{T}$ 's explicit inclusion in the equations and the parameter set. Still, the reader's ability to use the model would not be inhibited by ignoring this extra mathematics.

\section{Binding Parameters}

If $k_{o n}$ has not been determined by a surface plasmon resonance method (Tang et al., 2010), or other methods, such as KinExA (Wani et al., 2016), $k_{\text {on }}$ can be assumed to be $1 e 6 \mathrm{M}^{-1} \mathrm{~s}^{-1}$ (Foote and Eisen, 1995). Given a measured constant of dissociation $\left(K_{D}\right)$, one can calculate $k_{\text {off }}$ as the product of $k_{\text {on }}$ and $K_{D}$. Drug:target interactions in the peripheral compartment and complex distribution from plasma to the peripheral compartment are typically ignored. To make binding interactions even more mechanistic, one can include step-wise binding for each of the antibody's arm. In this case the binding interactions from Eqs 1-7 would need to be rewritten as follows:

$$
\begin{aligned}
& \frac{d D_{P}}{d t}=\ldots+k_{\text {off }} C_{P}-2 k_{o n} D_{P} T_{P} \\
& \frac{d D_{S}}{d t}=\ldots+k_{o f f} C_{S}-2 k_{o n} D_{S} T_{S}
\end{aligned}
$$

$$
\begin{gathered}
\frac{d C_{P}}{d t}=\ldots+2 k_{o n} D_{P} T_{P}-k_{o f f} C_{P}-k_{o n} C_{P} T_{P}+2 k_{o f f} C_{P 2} \\
\frac{d C_{S}}{d t}=\ldots+2 k_{o n} D_{S} T_{S}-k_{o f f} C_{S}-k_{o n} C_{S} T_{S}+2 k_{o f f} C_{S 2} \\
\frac{d T_{P}}{d t}=\ldots+k_{o f f} C_{P}-2 k_{o n} D_{P} T_{P}-k_{o n} C_{P} T_{P}+2 k_{o f f} C_{P 2} \\
\frac{d T_{S}}{d t}=\ldots+k_{o f f} C_{S}-2 k_{o n} D_{S} T_{S}-k_{o n} C_{S} T_{S}+2 k_{o f f} C_{S 2} \\
\frac{d C_{P 2}}{d t}=k_{s p C} C_{S 2} \frac{V_{S}}{V_{P}}-k_{p s C} C_{P 2}+k_{o n} D_{P} T_{P}-k_{o f f} C_{P}-k_{e l C} C_{P 2} \\
\frac{d C_{S 2}}{d t}=k_{p s C} C_{P 2} \frac{V_{P}}{V_{S}}-k_{s p C} C_{S 2}+k_{o n} D_{S} T_{S}-k_{o f f} C_{S 2}
\end{gathered}
$$

For variables $D_{P}, D_{S}, T_{P}, T_{S}, C_{P}, C_{S}$, the only differences between Eqs 11-18 and Eqs 1-7 are the binding interactions, hence synthesis, distribution, and elimination reactions are replaced by ellipses for simplicity. Two new species are introduced: $C_{P 2}$ and $C_{S 2}$, which represent the concentration of $\mathrm{mAb}$ bound to its target on each arm (a double complex) in plasma and the SoA, respectively. The factors of two account for the multiple ways in which an unbound antibody can engage a target, or a doubly bound antibody can release a target. Whether to include this mechanistic binding step is dependent on the biology and the requirement for this extra complexity.

\section{Target Parameters}

The target related parameters are turnover (half-life or degradation rate), synthesis rate, concentrations (both in 
plasma and the SoA) and distribution rate (between the plasma and the SoA).

\section{Estimating Target Concentrations}

There are many published methods or approaches for measuring target levels both in serum and tissue (Becker and Hoofnagle, 2012), including ligand binding assays and mass spectrometry. A preferred approach, as previously highlighted due to its enhanced specificity and selectivity, is protein or peptide immunoaffinity liquid chromatography tandem mass spectrometry (IA LC-MS/MS). The method requires selection of optimal capture reagents, calibration standards and surrogate peptides for detection. In this method, proteins and/or trypsin digested peptides are enriched by anti-protein or anti-peptide antibodies or a sequential combination of both approaches. The enriched peptides are quantified using detection by nanoflow LC-MS/MS. A detailed description of this method can be found in Palandra et al. (2013) and Neubert et al. (2020). The addition of a stable isotope-labeled synthetic version of the surrogate peptide(s) prior to protein digestion reduces variables and quantitation relative to the chosen protein calibrator can be achieved. The mass spectrometric response of the endogenous peptide is compared to the analogous response for the labelled peptide in all samples, including calibrators, thereby normalizing for digestion efficiency and matrix suppression differences between the samples (Bantscheff et al., 2007). Examples of well designed, fit for purpose, sequential protein and tryptic peptide IA-LC-MS can achieve lower limit of quantitation (LLOQ) of sub $10 \mathrm{pg} / \mathrm{ml}$ (Neubert et al., 2013; Palandra et al., 2013), while protein IA and peptide IA only approaches are typically capable of achieving sub 100 pg/ml LLOQ (McAvoy et al., 2014; Zhao et al., 2018; Shuford et al., 2020).

Target expression levels vary widely depending on their biological function, disease state, tissue localization, and many other factors. For example, the growth and differentiation factor 8 (GDF-8), is present in circulation at very high expression levels of approximately $7 \mathrm{ng} / \mathrm{ml}$ in adult humans owing to its function in regulating muscle mass (Palandra et al., 2016). While targets like Interleukin-21 are not detected in human serum and can only be measured in certain human tissues such as colon tissue at an average concentration of $1 \mathrm{ng} / \mathrm{g}$ (Palandra et al., 2013). The alarmin cytokine, Interleukin-33 (IL-33) is present in circulation at approximately $20-100 \mathrm{pg} / \mathrm{ml}$ (Artru et al., 2020) and in many tissues at very elevated concentrations $(200 \mathrm{ng} / \mathrm{g}$ in the lung (Cohen et al., 2015)) owing to its ubiquitous presence in the nucleus of all producing human cells. When the concentrations in a tissue homogenate are measured, the concentrations that are provided need to be adjusted for the interstitial volume of the analyzed tissue before being applied in the SoA model. Again, other methodologies have been used in some cases as driven by the protein and analytical complexities.

\section{Estimating Target Turnover}

While traditionally radio-labelling methods have been used for estimating turnover, methods based on in-vivo stable isotope labelling and proteomics have been established to measure physiologically relevant turnover (Bateman et al., 2006; Lindwall et al., 2006; Doherty and Whitfield, 2011; Hinkson and Elias, 2011;
Lassman et al., 2014; Larance and Lamond, 2015). One of the preferred methods uses immunoaffinity enrichment of the target proteins from a stable isotope labeled amino acid tracer pulse-chase study, either from preclinical or clinical studies. Tracer incorporation in a surrogate peptide sequence is then measured by targeted mass spectrometry. The workflow and details of the study have been published (Farrokhi et al., 2018a). Once data is available for both the tracer levels and its incorporation in the protein of interest, the turnover rate is estimated using a series of models that account for the tracer's incorporation, as well as the known biological properties of the protein of interest (e.g., a shed receptor in the tissue vs cytokine released primarily in plasma). An earlier version of these models was used in Farrokhi et al. 2018a These assays are confined by the time limitations in pulse-chase durations (multiple hours or a few days) in in vivo studies and accurate measurement of slow turnover rates (i.e., multiple days or weeks) are not feasible or are estimated from extrapolation. Also, in some cases, measurements are not feasible due to low concentrations of the target protein. Other methodologies have also been published in the literature, (Bateman et al., 2006; Lindwall et al., 2006; Doherty and Whitfield, 2011; Hinkson and Elias, 2011; Lassman et al., 2014; Larance and Lamond, 2015), but they are likely to experience similar limitations. Physiological target turnover measurements in human is limited to only the soluble targets and turnover in SoA is estimated from soluble target when possible.

\section{Target Synthesis Rate}

Generally, once information about the target's concentrations and turnover are available, the synthesis is calculated assuming that in the absence of drug the system is at steady state. The rate constant for target distribution from the plasma to the site of action $\left(k_{p s T}\right)$ can be fixed. The rate constant for target distribution from the site of action to the plasma $\left(k_{s p T}\right)$ is derived based on the steady state levels of target in the plasma and the SoA together with $k_{p s T}$. At steady state, synthesis rates, degradation rates, and distribution rate constants between the plasma and the SoA must be balanced to achieve known levels of target concentrations in both compartments.

Target steady state concentration in plasma prior to drug administration is defined by:

$$
\frac{d T_{P}}{d t}=k_{s y n P}-T_{P 0}\left(k_{d e g T p}+k_{p s T}\right)+T_{S 0} k_{s p T} V_{S} / V_{P}=0
$$

Target steady state concentration at the SoA prior to drug administration is defined by:

$$
\frac{d T_{S}}{d t}=k_{s y n S}-T_{S 0}\left(k_{d e g T s}+k_{s p T}\right)+T_{P 0} k_{p s T} V_{P} / V_{S}=0
$$

Total target synthesis in the human body (in amount, nanomoles) is defined as:

$$
k_{\text {synTot }}=k_{\text {synP }} V_{p}+k_{\text {syns }} V_{S}=T_{P 0} k_{\text {degTp }} V_{P}+T_{S 0} k_{\text {degTs }} V_{S}
$$

It is rare that one has information about the ratio between target synthesis in plasma versus the SoA. This ratio is generally assumed taking into account what is known about the biology. For the remainder of this section and for the purpose of equations 
and calculations, the fraction of total synthesis in the SoA is captured by the parameter frac.

\section{Estimating Target Distribution}

While drug distribution constants can be calculated from the PK and Eqs 8-10 above, target rates of distribution are largely unknown. We fix $k_{p s T}$ :

$$
k_{p s T}=\frac{Q_{\text {target }}}{V_{P}} .
$$

At an exploratory stage, we use a parameter value for $Q_{\text {target }}$, estimated from literature data reporting a distributive clearance rate of Albumin from Synovial joints of Rheumatoid arthritis patients (Owen et al., 1994). While this parameter value can be used in the initial stages of a project, as a project progresses, this value is explored in more detail and is updated by considering a pharmacokinetics based value for a recombinant version of the target, e.g., (Creaven et al., 1987; Banks et al., 2000; Zhang et al., 2019), or by basing $Q_{\text {target }}$ on the molecular weight of the target (Li et al., 2017).

Since these approaches have not be largely validated and adopted, one is advised to employ sensitivity analysis regarding target distribution parameters.

If $k_{p s T}$ is fixed, assuming $k_{s y n s}=f r a c * \frac{k_{s y n T o t}}{V_{S}}$ and rearranging Eqs 19 and 22 will result in:

$k_{s p T}=f r a c \frac{\left(T_{P 0} k_{\operatorname{deg} T p} V_{P}+T_{S 0} k_{\operatorname{deg} T s} V_{S}\right)}{T_{S 0} V_{S}}-k_{d e g T s}+\frac{T_{P 0} V_{P}}{T_{S 0} V_{S}} * k_{p s T}$

\section{APPLICATIONS OF SITE-OF-ACTION MODEL METHODOLOGY}

This section provides four examples of application of the SoA modeling structure to soluble targets. The examples are divided into the three main categories for successful use of translational modeling and simulation: right target, right compound, and right dose.

\section{Right Target}

In the pre-clinical space, especially in early project stages, it is appropriate to conduct feasibility analysis. At this stage, a successful assessment is both one that progresses a target as a part of the portfolio and eventually into the clinic, as well as one that shows that a target is infeasible from a clinical utility standpoint. Such analyses are performed to determine whether sufficient levels of target coverage can be achieved via neutralization with a monoclonal antibody and should not be confused with determining whether the target is "right" from a disease standpoint. Often these analyses are done with just invitro functional assays, whose utility is limited - they capture a narrow aspect of the biology and may be done in the pre-portfolio stage. Once the project is part of the portfolio, we recommend a more thorough analysis with a SoA model since more resources for modeling and biomeasures/biomarkers are available. In many cases, the required levels of target coverage for efficacy are unknown so a threshold is set, depending on the disease, competitive landscape, and other factors, often at $>90 \%$ or $>99 \%$ target neutralization. If the required coverage for pharmacology cannot be achieved at a commercially viable dose, project termination is recommended.

\section{Osteopontin Example}

The first example in this section is an example of the lattertargeting osteopontin for rheumatoid arthritis (RA). Osteopontin is a secreted protein from a plethora of cells, that has been implicated in a variety of biological functions, from inflammation and fibrosis, to tumorigenesis and metastasis (Ashkar et al., 2000; Lund et al., 2013; Wang et al., 2014; Liu et al., 2015; Clemente et al., 2016). The goal of the work was to assess feasibility in suppressing osteopontin for the treatment of RA. A full SoA model was not utilized in this case because, as you will see, plasma levels of osteopontin were high enough to sufficiently inform feasibility, without the need for further modeling complexity. Target turnover was estimated using a human D3-leucine pulse-chase study similar to discussed in Estimating Target Turnover. Target serum concentrations were measured using a nano flow liquid chromatographytandem mass spectrometry method similar to discussed in Estimating Target Concentrations. Mean serum concentrations were measured at around $10 \mathrm{nM}$ and half-life was estimated at around $10 \mathrm{~min}$. The scenarios presented here assume a mAb interacting with a soluble target and PK parameters for the drug are in Table 3. For the purpose of the example, to assess the degree of target coverage (free target reduction) in plasma, two dosing regimens were explored $300 \mathrm{mg}$ SC and $1,000 \mathrm{mg}$ IV, both every week. These are not commercially viable doses for RA but were selected to explore the maximum attainable coverage with a monoclonal antibody targeting osteopontin. The effect of antibody affinity on target coverage was simulated using $K_{D}$ values of $1 \mathrm{nM}, 100 \mathrm{pM}$, for both scenarios, and $10 \mathrm{pM}$ for the IV dosing scenario. The results of the simulations can be seen in Figures 2 and 3. Ultimately, the high target levels and very fast target turnover resulted in low target trough coverage even at a non-commercially viable dosing regimens for RA. Drug affinity for the target was predicted to have little effect on the coverage, so affinity optimization would not help. Therefore, the target was determined undruggable with a regular monoclonal antibody and the project was not progressed. More detailed assessment of this target with a different modeling approach can be seen in Farrokhi et al. 2018b, where other antibody modalities were also explored.

\section{IL-33 Example}

Another feasibility example is IL-33. IL-33 is an alarmin, member of the IL-1 cytokine family, released by cells at the barrier surfaces (i.e., keratinocytes and airways epithelial cells) after disruption in the barrier function by pathogens, tissue injury, and cell death, and has been associated with atopic dermatitis and asthma (Saluja et al., 2015; Saluja et al., 2016). Asthma is the disease of choice for this example, therefore the SoA is lung. IL-33 signals through binding to ST2 and then forming a heterodimer with the IL-1 
TABLE 3 | Antibody PK parameters for osteopontin feasibility analysis.

\begin{tabular}{lcc}
\hline Parameter & Value (unit) & References \\
\hline$V_{P}$ & $3.2(\mathrm{~L})$ & \\
$V_{2}$ & $2.2(\mathrm{~L})$ & Betts et al. (2018) \\
$\mathrm{Cl}$ & $0.454(\mathrm{~L} / \mathrm{d})$ & \\
$Q$ & $0.252(\mathrm{~L} / \mathrm{d})$ & \\
$k_{a}$ & $0.26(1 / \mathrm{d})$ & Assumed, (Dirks and Meibohm, 2010) \\
$F$ & $60(\%)$ & \\
\hline
\end{tabular}

receptor (Saluja et al., 2015; Saluja et al., 2016; Griesenauer and Paczesny, 2017). ST2 can also be found in soluble form (sST2), which is a scavenger for IL-33 and constraints its signaling properties (Griesenauer and Paczesny, 2017). For the purpose of this example, our antibody competes with sST2 for binding to IL-33 in plasma. A scheme and description of the model is shown in Figure 4. The antibody binds IL-33 both in plasma and at the SoA. The distribution of the drug to the SoA and the periphery as well as assumptions regarding the mAb:IL-33 complex have been described earlier (see Drug Distribution Parameters). The target-related parameters and references used are described in Table 4. The mAb related parameters are described in Table 3 and Binding Parameters. $K_{D}$ for the purpose of this feasibility analysis was assumed to be either 100 or $10 \mathrm{pM}-k_{\text {on }}$ remained fixed (see Binding Parameters), while $k_{\text {off }}$ was calculated accordingly. Figure 5 shows projected target coverage at the site of action (lung). Based on the modeling results, the $100 \mathrm{mg} \mathrm{SC}$ Q4W dose is predicted to achieve greater than $90 \%$ neutralization of IL-33 at the site of action if the affinity of the mAb is closer to $10 \mathrm{pM}$ than $100 \mathrm{pM}$. While a $\sim 10 \mathrm{pM}$ affinity is challenging from an engineering perspective, design of a high-affinity antibody should be expected when targeting cytokines, especially if the ligand's binding to its natural receptor is so tight (26 pM (Palmer et al., 2008)). In this case it was concluded, using the modelling analysis, that the target should be explored further, however extensive affinity optimization will likely be required to achieve sufficient neutralization. A Matlab Simbiology model file for this example is available in the Supplement section of this article.

This early-stage feasibility analysis omits several potentially important aspects of the biology of IL-33, e.g., quick inactivation due to oxidation and proteolytic activities, and synthesis in cellular nucleus and release under inflammatory conditions (Cohen et al., 2015; Saluja et al., 2015; Griesenauer and Paczesny, 2017; Scott et al., 2018). The former can increase the apparent clearance of active IL-33 and both properties can skew the measurements of active free IL-33 in plasma and tissue. Also, considering the tight binding of IL-33 to sST2, further considerations can be made regarding the expression of membrane ST2 in the lung and the antibody's interaction with the target in a full receptor:target interaction mechanistic modeling system. Potentially, a competing vs non-competing epitope may be important for enhancing target neutralization, which could be evaluated at the next stage of mechanistic modeling - right molecule. Several anti-IL-33 molecules have already been in the clinic, and a couple have shown positive

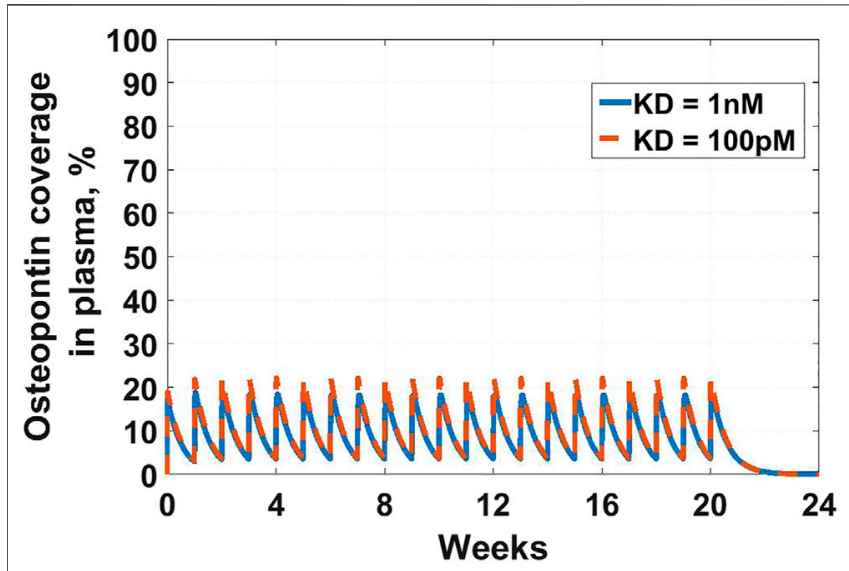

FIGURE 2 | Osteopontin coverage in plasma: Shows the projected neutralization of osteopontin after mAb administration as described in Osteopontin Example. Simulated dose is $300 \mathrm{mg}$ SC Q1W, with two antibody affinities $-K_{D}$ of $1 \mathrm{nM}$ (solid blue line) and $100 \mathrm{pM}$ (dashed orange line). Even peak projected neutralization is only $20 \%$, which is unlikely to result in meaningful pharmacology.

results in asthma (Anaptysbio, 2014; Regeneron Pharmaceuticals, 2019), validating the model's conclusions.

\section{Right Compound}

Once feasibility has been established, the team delves deeper into assessing the molecular properties of the antibody necessary to neutralize the target. Most of the pharmacokinetic properties would depend on molecular assessment and there are currently few models that connect antibody molecular assessment and pharmacokinetics (Jones et al., 2019; Jones et al., 2020). Predominantly, modelers can assist the engineering team with projecting what antibody binding affinity is needed for the required level of neutralization (coverage). We use the next example of a clinical compound, to assess whether the mechanism was tested adequately and what affinity is required for improved target neutralization at a commercially viable dose.

Chemokine (C-C motif) ligand 20 (CCL20) is a chemoattractant for lymphocytes and dendritic cells in a variety of mucosal tissues (Schutyser et al., 2003). GSK3050002 is an anti-CCL20 monoclonal antibody that was tested in healthy volunteers (Bouma et al., 2017). The data presented in the study was drug, drug:target complex, and free target concentrations both in serum and in skin blister. The drug did not appear to inhibit monocytes and granulocytes activity in the skin blister model, so we decided to test whether a higher affinity antibody would be predicted to achieve higher and more sustained target coverage at the skin. For this purpose, a SoA model was constructed with skin as the SoA with the assumption that CCL20 was synthesized in the skin only and eliminated in the plasma only. Interstitial skin volume was assumed to be $1.125 \mathrm{~L}$ (Shah and Betts, 2012). Two-compartment PK model parameters (Table 4), $K_{D}$ (350 pM), target half-life $(15 \mathrm{~min})$, plasma:skin drug concentration ratio (20\%, measured), and initial CCL20 concentrations in the plasma $(30 \mathrm{pM})$ were fixed based data 


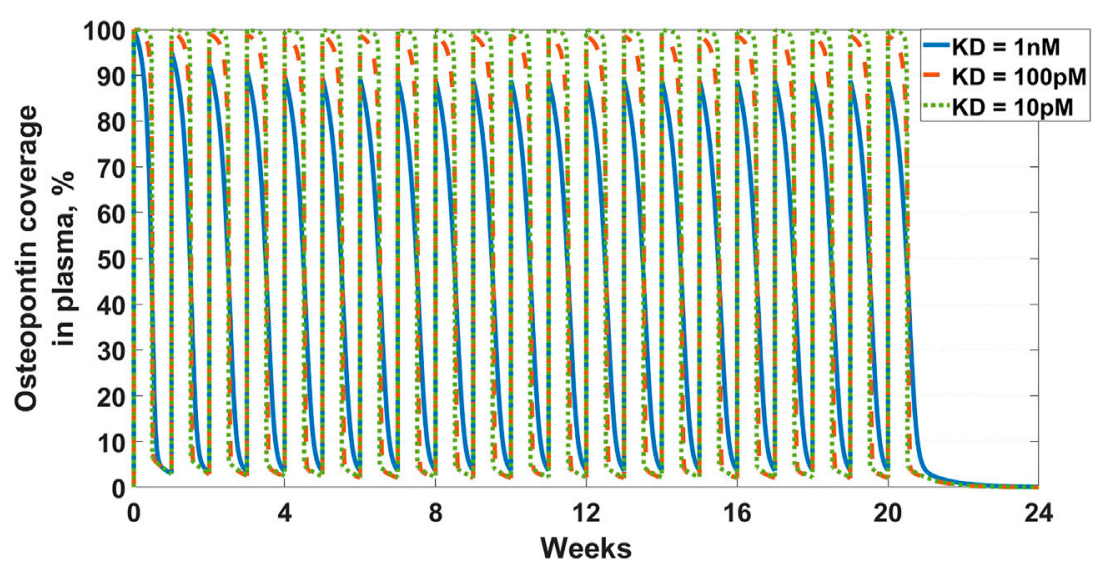

FIGURE 3 | Osteopontin coverage in plasma: Shows the projected neutralization of osteopontin after mAb administration as described in Osteopontin Example. Simulated dose is 1,000 mg IV Q1W, with three antibody affinities $-K_{D}$ of $1 \mathrm{nM}$ (solid blue line), $100 \mathrm{pM}$ (dashed orange line), and 10 pM (dotted green line). All scenarios result in high peak neutralization, which is not sustained for the full duration of the dosing interval.

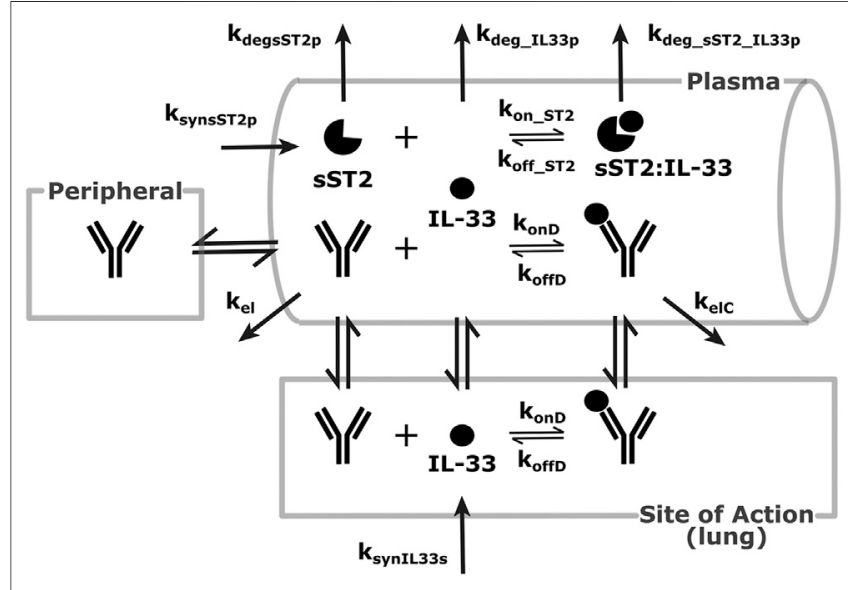

FIGURE 4 | Modeling scheme of an anti-IL-33 mAb. The general processes are similar to the default scheme described in Figure 1, with several details adapted to the IL-33 scenario. IL-33 is synthesized at the SoA (lung) and distributes to the plasma. There, it can bind SST2 or get eliminated. sST2 is synthesized and eliminated in plasma only. The SST2:IL-33 complex clears in the plasma.

provided in Bouma et al., 2017. Skin concentrations of CCL20 are assumed to be 10-fold higher than plasma. Under these assumptions, even a dose of $20 \mathrm{mg} / \mathrm{kg}$ is not projected to achieve $90 \%$ target reduction in the skin for more than $\sim$ a week (Figure 6). At a regimen of $300 \mathrm{mg} \mathrm{SC} \mathrm{Q2W}$, the $\mathrm{mAb}$ is projected to need an affinity of $3.5 \mathrm{pM}$ in order to reduce the target by $90 \%$ (Figure 7). This suggests that the affinity of the $\mathrm{mAb}$ was not tight enough and that the CCL20 mechanism was likely not adequately tested in the published clinical study.

While the general conclusion may still hold, several assumptions affect the results of the model. Some, like the synthesis of CCL20 in the skin, are reasonable given that the disease of interest is atopic dermatitis. The SoA:plasma ratio was assumed similar to the one found in IL-33 (see Table 5). That ratio would be target-dependent and potentially sensitivity analysis would need to be done to fully evaluate.

\section{Right Dose}

Once drug properties have been established, modeling is utilized to project a clinical efficacious dose in different patient populations. This step is important both from standpoint of selecting doses for toxicology studies and assisting in dose selection for first-in-human studies. This particular example is a retrospective analysis of the clinical compound IMA-026, an antagonist monoclonal antibody against IL-13 (Gauvreau et al., 2011; Kasaian et al., 2011; Tiwari et al., 2016b). IL-13 is a cytokine with demonstrated role in many inflammatory diseases, including asthma. IMA-026 is an M1 type anti-IL-13 antibody (May and Fung, 2015), which blocks IL-13 from interaction with its receptors - IL13Ra1 (signaling receptor) and IL13Ra2 (decoy receptor) (Chandriani et al., 2014). IMA-026 data in healthy volunteers (NCT00517348) has been analyzed before (Tiwari et al., 2016b), where initial IL-13 concentrations, drug affinity, and target turnover were estimated. However, we demonstrate here that the accumulation of total plasma concentration of IL-13 can be obtained without fitting any parameters by using literature references (target turnover), pre-clinical observations (drug affinity), and relevant clinical data (PK and initial target concentrations). IL-13 target turnover was estimated to be around $20 \mathrm{~min}$ in mice (Khodoun et al., 2007), drug $K_{D}$ was $1 \mathrm{nM}$ (based on internal measurements), median initial plasma IL-13 concentrations were estimated using ligand binding assay (LBA) to be around $0.06 \mathrm{pM}$ for healthy volunteers and $0.12 \mathrm{pM}$ for asthmatic patients, and PK parameters were estimated in Tiwari et al., 2016b. A SoA model was constructed with interstitial lung volume of $0.3 \mathrm{~L}$ (Shah and Betts, 2012) and SoA target concentrations of $0.03 \mathrm{pM}$ in healthy volunteers and $0.4 \mathrm{pM}$ in asthmatic patients (Kroegel et al., 1996). An average human bodyweight of $70 \mathrm{~kg}$ was assumed. Figure $\mathbf{8}$ shows the simulation of total IL-13 accumulation using the SoA model in plasma along with the observed clinical data from the healthy 


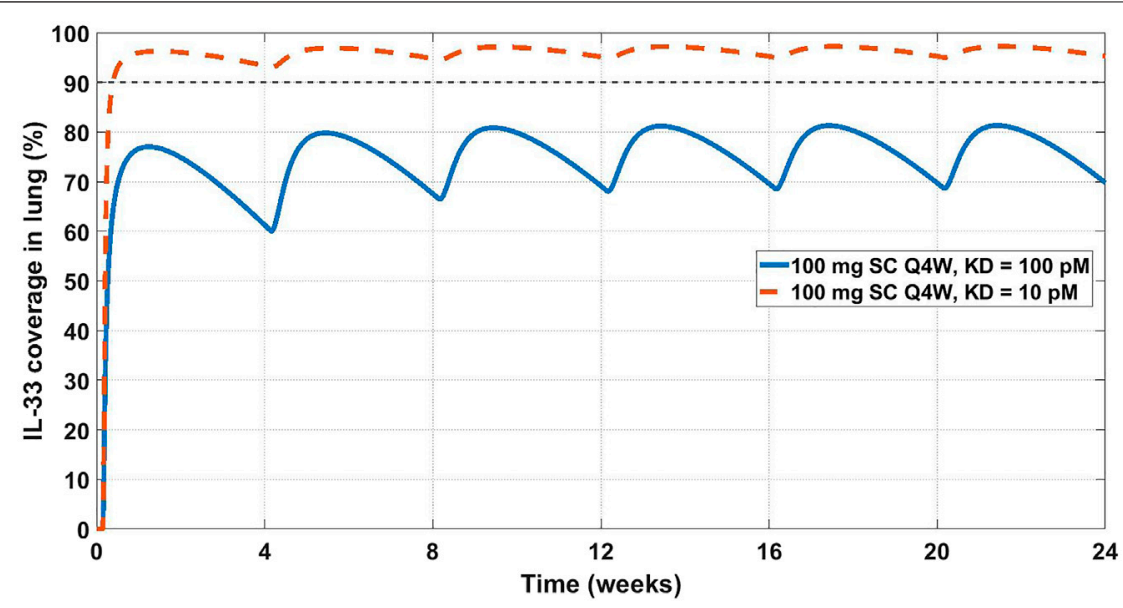

FIGURE 5 | Projected IL-33 neutralization in the lung at $100 \mathrm{mg} \mathrm{SC} \mathrm{Q4W} \mathrm{dosing} \mathrm{at} 10 \mathrm{pM}$ (dashed orange line) and $100 \mathrm{pM}$ (solid blue line) drug affinities. The $90 \%$ coverage line (dashed grey) is emphasized for convenience. The model projects that a $10 \mathrm{pM}$ affinity would achieve $90 \% \mathrm{IL}-33$ neutralization in the lung.

TABLE 4 | GSK3050002 two-compartment PK parameters (Bouma et al., 2017).

\begin{tabular}{lcc}
\hline Parameter & Value (unit) & $\mathbf{9 5 \%} \mathbf{~ l ~}$ \\
\hline$V_{P}$ & $3.63(\mathrm{~L})$ & $3.44-3.83$ \\
$V_{2}$ & $3.19(\mathrm{~L})$ & $2.89-3.52$ \\
$\mathrm{Cl}$ & $0.475(\mathrm{~L})$ & $0.439-0.514$ \\
$Q$ & $0.374(\mathrm{~L} / \mathrm{d})$ & $0.324-0.432$
\end{tabular}

volunteer study. IMA-026 was evaluated further in an additional clinical study, NCT00725582, Study Evaluating the Effect of IMA026 on Allergen-Induced Late Asthma Response in Mild Asthma. Two $2 \mathrm{mg} / \mathrm{kg}$ SC doses were administered 1 week apart.

The SoA model estimated that after 2 weeks dosing of $2 \mathrm{mg} / \mathrm{kg}$ SC Q1W the drug reached only around $8 \%$ target suppression at the site of action, while 8 weeks of dosing of $30 \mathrm{mg} / \mathrm{kg}$ SC Q1W would have achieved close to $90 \%$ coverage (Figure 9). Ultimately IMA-026 was abandoned since it did not show efficacy (Gauvreau et al., 2011). However, had data supporting an SoA model been available at time of the study conception, it could have projected the low coverage at $2 \mathrm{mg} / \mathrm{kg}$ and suggested either a longer duration study or a more appropriate dose for testing the mechanism. Likely, if SoA modeling had been available even earlier, an affinity maturation campaign could have been initiated to increase the affinity above $1 \mathrm{nM}$ since a dose of $30 \mathrm{mg} / \mathrm{kg}$ Q1W is not commercially feasible. Suggestions for increased dose or improved affinity are corroborated by a crowd of anti-IL-13 monoclonal antibodies that have subsequently shown moderate to low efficacy in asthma (Gauvreau et al., 2011; Noonan et al., 2013; van Hartingsveldt et al., 2013; De Boever et al., 2014; Hanania et al., 2016), indicating the difficulty of achieving complete neutralization of IL-13 and/or its role as a standalone mechanism in the disease. The only anti-IL-13 mAb that has been in Phase 3 for asthma is lebrikizumab, with reported affinity of $<10 \mathrm{pM}$ (Ultsch et al., 2013). Lebrikizumab is currently in development for atopic dermatitis with positive results (Guttman-Yassky et al., 2020). Tralokinumab, whose affinity is reported at $58 \mathrm{pM}$ (Popovic

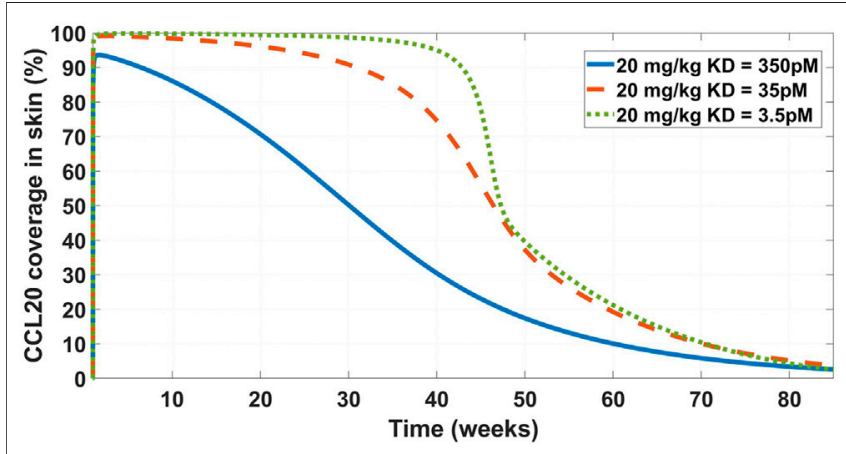

FIGURE 6 | Model projected CCL20 coverage in the skin after administration of $20 \mathrm{mg} / \mathrm{kg}$ IV bolus dose of GSK3050002. Three mAb affinity scenarios were modeled - $350 \mathrm{pM}$ (solid blue line), $35 \mathrm{pM}$ (dashed orange line), and $3.5 \mathrm{pM}$ (dotted green line). The low coverage at the base $K_{D}$ of $350 \mathrm{pM}$ is consistent with observed lack of activity as described in Bouma et al. 2017.

et al., 2017), has been approved for treatment of atopic dermatitis (LEO Pharma announces, 2021). The success and high affinity of both mAbs validate the model's conclusions.

\section{DISCUSSION}

We have presented a three compartment mechanistic model that extends a typical two-compartment model by adding a site of action - a representation of the interstitial volume of the tissue where the interactions of the protein target with the drug are expected to contribute to disease modulation. The modeling is performed through a system of ordinary differential equations and is a mechanistic representation of the interaction of the drug with the target. The framework can be used for constructing a fit-forpurpose model to evaluate whether a target is biologically relevant and hitting the target is feasible (right target), guide drug properties 
TABLE 5 | List of target-related parameters used for anti-IL-33 model.

\begin{tabular}{|c|c|c|c|}
\hline Parameter & Description & Value, units & Comments and references \\
\hline IL33s_0 & $\begin{array}{l}\text { Initial concentration of free IL- } \\
33 \text { at the SoA (lung) }\end{array}$ & $11 \mathrm{pM}$ & $\begin{array}{l}200 \text { pg/mg of lung tissue in COPD or asthmatic patients } \\
\text { (Cohen et al., 2015) }\end{array}$ \\
\hline IL33p_0 & $\begin{array}{l}\text { Initial concentration of free IL- } \\
33 \text { in plasma }\end{array}$ & $1.5 \mathrm{pM}$ & $\begin{array}{l}\text { Assumed similar between asthma and allergic rhinitis - } \\
27 \text { pg/ml (Glück et al., 2019) }\end{array}$ \\
\hline sST2_0 & $\begin{array}{l}\text { Initial concentration of free } \\
\text { sST2 in plasma }\end{array}$ & $27 \mathrm{pM}$ & $\begin{array}{l}1 \mathrm{ng} / \mathrm{ml} \text { in mild/moderate attack ((Oshikawa et al., 2001)), } \\
\text { within two-fold of most other situations in Oshikawa et al. } \\
\text { (2001) and levels in Glück et al. (2019) }\end{array}$ \\
\hline sST2_IL33p_0 & $\begin{array}{l}\text { Initial concentration of SST2- } \\
\text { bound IL-33 in plasma }\end{array}$ & 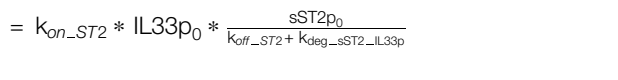 & To preserve drug-free equilibrium values \\
\hline $\begin{array}{l}\text { IL-33 molecular } \\
\text { weight }\end{array}$ & $\begin{array}{l}\text { To convert mass } \\
\text { concentration into molarity }\end{array}$ & $18 \mathrm{kDa}$ & Palmer et al. (2008) \\
\hline $\begin{array}{l}\text { sST2 molecular } \\
\text { weight }\end{array}$ & $\begin{array}{l}\text { To convert mass } \\
\text { concentration into molarity }\end{array}$ & $37 \mathrm{kDa}$ & Mueller and Dieplinger, (2016) \\
\hline Kdeg_IL33p & $\begin{array}{l}\text { Degradation rate of IL-33 in } \\
\text { plasma }\end{array}$ & $4.21 /$ day & 4 h half-life in human lung explants (Cohen et al., 2015) \\
\hline $\mathrm{K}_{\text {deg_ssT2p }}$ & $\begin{array}{l}\text { Degradation rate of sST2 in } \\
\text { plasma }\end{array}$ & $2.61 /$ day & $\begin{array}{l}6.3 \text { h half-life (recombinant, IV administration) (Jacobs } \\
\text { et al., 1993) }\end{array}$ \\
\hline K deg_ssT2_IL33p & $\begin{array}{l}\text { Degradation rate of sST2:IL- } \\
33 \text { complex in plasma }\end{array}$ & $=\mathrm{k}_{\text {deg }_{-} \mathrm{sST} 2 \mathrm{p}}$ & Assumed \\
\hline kon_ST2 & $\begin{array}{l}\text { Association constant } \\
\text { between IL-33 and sST2 }\end{array}$ & 358 1/nM/day & Palmer et al. (2008) \\
\hline $\mathrm{k}_{\text {off_ST2 }}$ & $\begin{array}{l}\text { Dissociation rate between IL- } \\
33 \text { and SST2 }\end{array}$ & $=\mathrm{K}_{\mathrm{on} \_\mathrm{ST} 2} * \mathrm{~K}_{\mathrm{D} \_ \text {IL33_sST2 }}$ & $\mathrm{K}_{\mathrm{D} \_I L 33 \_s S T 2}=26$ pM (Palmer et al., 2008) \\
\hline $\mathrm{k}_{\mathrm{ps} \_I L 33}$ & $\begin{array}{l}\text { IL-33 distribution rate from } \\
\text { plasma to SoA }\end{array}$ & $0.131 /$ day & See Estimating Target Distribution \\
\hline $\mathrm{k}_{\mathrm{sp} \_I L 33}$ & $\begin{array}{l}\text { IL-33 distribution rate from } \\
\text { SoA to plasma }\end{array}$ & 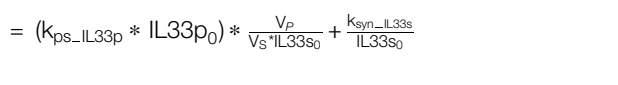 & To preserve drug-free equilibrium values \\
\hline $\mathrm{K}_{\text {syn_IL33s }}$ & $\begin{array}{l}\text { IL-33 synthesis rate at } \\
\text { the SoA }\end{array}$ & $=\left(\mathrm{k}_{\text {deg_IL33p }} *\right.$ IL33 $\left.\mathrm{p}_{0}+\mathrm{k}_{\text {deg_sST2_IL33p }} * \mathrm{sST} 2 \_I L 33 p_{0}\right) * \frac{V_{p}}{V_{S}}$ & To preserve drug-free equilibrium values \\
\hline $\mathrm{K}_{\text {syn_ssT2p }}$ & sST2 synthesis rate in plasma & 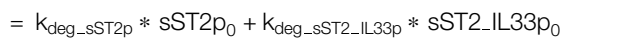 & To preserve drug-free equilibrium values \\
\hline
\end{tabular}

for sufficient target engagement (right compound) and inform the necessary doses for achieving the degree of target engagement required for efficacy in the clinic (right dose). While the case studies described were categorized into examples of each of these three questions, these questions are inter-linked and in practice the modelling approach addresses all three if used at an appropriate stage of the drug discovery process. Ideally at project inception, a model should be generated to explore feasibility, affinity, and PK requirements for a desired dose level. Such an approach allows drug companies to focus on programs with the highest chance of success and limit the "wasted" resources on those which are more likely to fail. Hence, our proposal is to utilize this model in the early stages of drug discovery and, if possible, validate with clinical data.

The main feature of the SoA modeling approach is its flexibility. Depending on the target, a modeler can include any number of SoA compartments, ranging from zero to including every main tissue in the human body. Along with the system of equations, we suggest two key biomeasures: target concentrations and turnover, which represent essential parameters in early stage pre-clinical work. This is evident in the examples we presented - osteopontin could not be covered at any reasonable dose or affinity because of its high abundance and turnover; IL-33 needed high affinity for high neutralization but was deemed feasible due to relatively low expression and slow turnover; CCL20 also needed high affinity and a high dose to neutralize due to fast turnover. Different targets have different associated biology and will require different strategies to overcome difficulties in neutralizing them. Hence, while for the purpose of this discussion we are focused on the modeling structure, a capable biomarkers/biomeasures group is essential for the translational research effort.

Within the SoA model framework one can implement a variety of biological complexities: downstream or upstream biomarkers, different cell types, ligand-receptor binding, etc. The SoA model facilitates their implementations but one must weigh the complexity of the model versus the questions it tries to answer. The SoA modeling approach is not appropriate for a full disease model, for that goal a more complex QSP implementation 


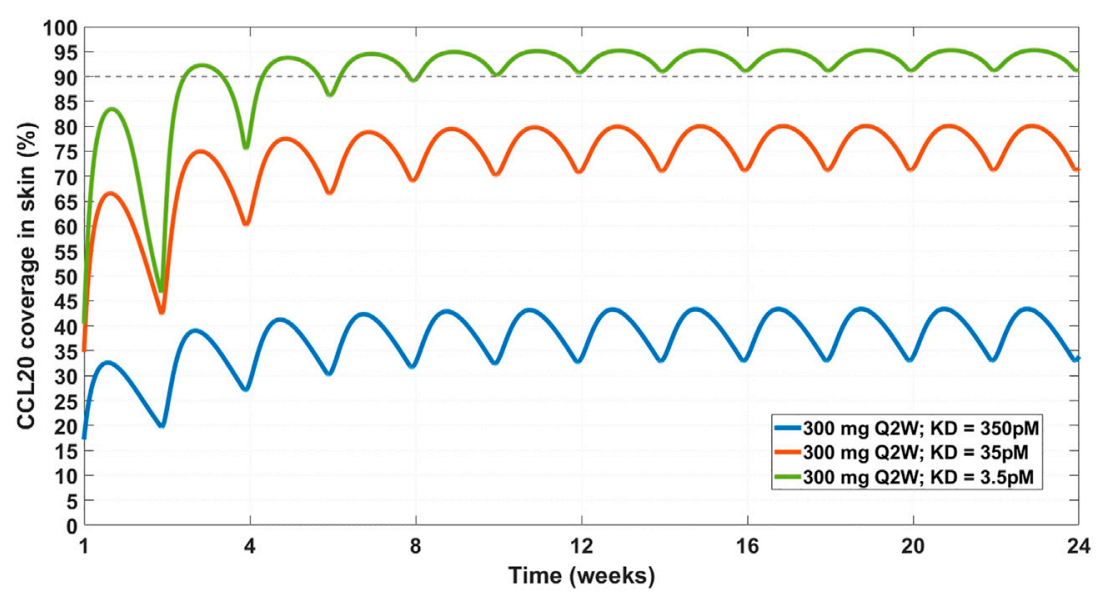

FIGURE 7| Projected CCL20 coverage in the skin at $300 \mathrm{mg} \mathrm{SC} \mathrm{Q2W} \mathrm{dosing} \mathrm{regimen} \mathrm{and} \mathrm{varying} \mathrm{affinity.} \mathrm{Three} \mathrm{affinity} \mathrm{scenarios} \mathrm{were} \mathrm{simulated} \mathrm{-} 350$ pM (solid blue line), $35 \mathrm{pM}$ (solid orange line), and $3.5 \mathrm{pM}$ (solid green line). Thin dashed grey line indicates $90 \%$ coverage, which is emphasized for convenience. The model projects that a $3.5 \mathrm{pM}$ affinity is required for achieving 90\% CCL20 coverage in the skin.

would be appropriate. The SoA model is also not a physiologically based pharmacokinetics (PBPK) model - if the distribution of the drug in the whole body is important for the project, a PBPK model would likely be the appropriate tool.

The SoA model, as presented here, is fit for mAb modeling with its representation of mechanistic target binding and unbinding. The model can be adjusted and has been utilized to incorporate different molecular modalities - pegylated Fab fragments, bispecific antibodies, etc.

The examples in the manuscript are focused on soluble targets, which simplified some aspects of the presentation. Membrane-bound targets often present different challenges from modeling standpoint (i.e., target-mediated drug

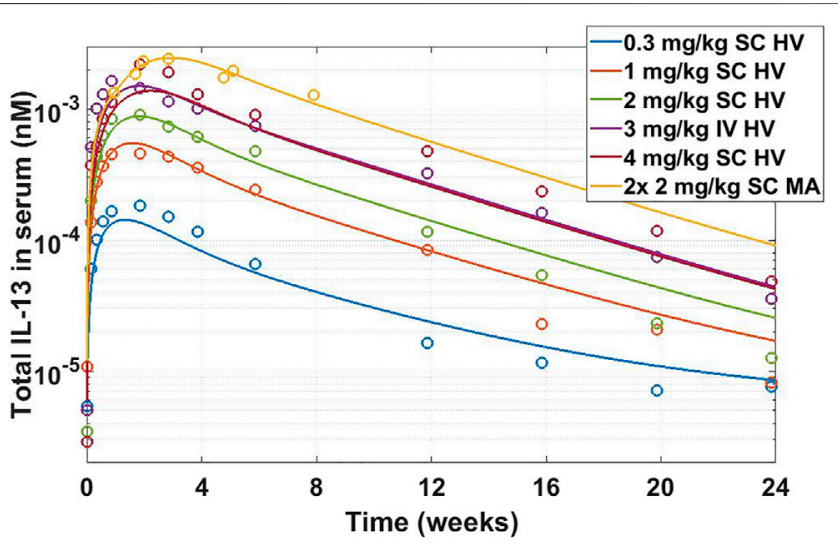

FIGURE 8 | Total IL-13 accumulation after IMA-026 administration in Phase I trial - model simulations vs published data. Different color solid lines correspond to different doses, open circles with corresponding colors are clinical data. Labels: SC, subcutaneous; IV, intravenous; HV, healthy volunteers; MA, mild asthmatics. The model reasonably captures the behavior using internal affinity measures, previously published target data, and published PK parameters for IMA-026, without fitting any parameters. disposition, shedding of the membrane target) and relevant biomarker and biomeasures assays (i.e., number of receptors per cell, quantifying receptor internalization). These aspects can be described in a separate manuscript but there are excellent discussions on the topic, among which Aston et al. 2011 and Grimm 2009.

There are a number of shortcomings to the SoA modeling platform. The peripheral compartment may be underutilized the model as presented here does not include target expression and turnover in the peripheral compartment or drug:target complex distribution in and out of the peripheral compartment. The method of fixing the ratio of drug concentration in plasma vs. the SoA assumes similar

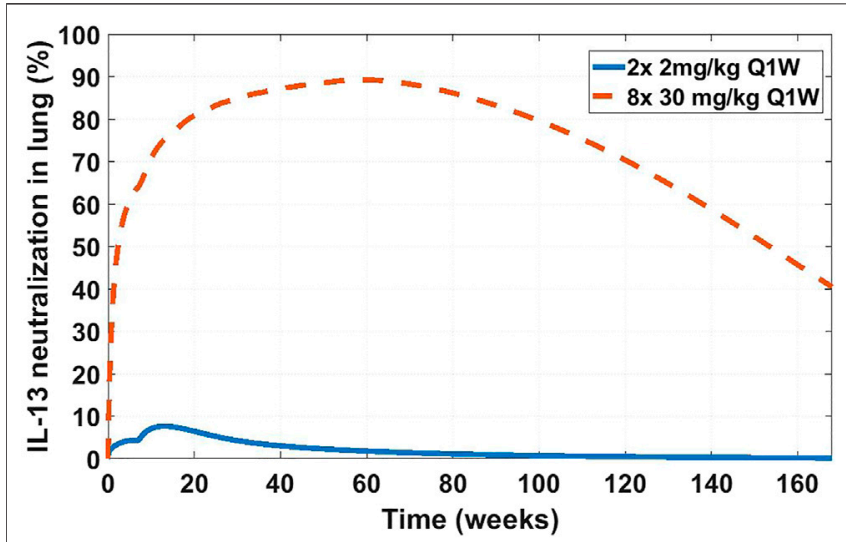

FIGURE 9 | Projected IL-13 neutralization in lung at two dosing schedules for IMA-026. Two doses of $2 \mathrm{mg} / \mathrm{kg}$ a week apart (solid blue line) was the clinically tested dose in asthma patients (NCT00725582). Eight doses of $30 \mathrm{mg} / \mathrm{kg}$ a week apart (dashed orange line) is a hypothetical clinical dose at which the projected IMA-026 coverage reaches close to $90 \% \mathrm{IL}-13$ neutralization in the lung. Modeling suggests that the mechanism of IL-13 neutralization was likely untested in the clinic due to low tested dose, which is projected to result in low coverage. 
distribution to other previously measured antibodies. The rate of distribution of the drug into the SoA may have an effect on the target neutralization, and here it is calculated. Some of the mathematical methods may lead to non-physiological rates in order to preserve the measured concentrations at steady state. For example, the use of target distribution fixes the rate of distribution from plasma to the SoA and calculates the rate of distribution from the SoA into the plasma when assuming that the target is only synthesized in the SoA. This can lead to non-physiological differences in the plasma:SoA back and forth distribution rates. The very assumptions of target synthesis and distribution can alter the estimate of target suppression. However, despite these potential caveats of the base SoA model described in this manuscript, it is possible to adapt the framework to capture the relevant biological mechanisms as appropriate so that the sought physiological modulation can be described more accurately. Therefore, all the assumptions and calculations presented in this manuscript are just the most current iterations of ideas and are subject to scrutiny in the face of new facts and better representations.

As with all models, this framework requires validation. Early decisions can be made with sparse data and limited measurements but in order to improve confidence in the modeling results, ideally, measurements of key dynamics behaviors predicted by the model (longitudinal measurements of target engagement, free or total target levels, etc.) in relevant species with the candidate molecule or a suitable surrogate are needed for model validation. Furthermore, a retrospective validation using clinical data (external clinical data can also inform the pre-clinical model) should be performed when data is available in order to bridge the gap between theoretical and practical model projections. Some aspects of these validations include clinically-relevant disease-dependent level of target neutralization, distribution of the $\mathrm{mAb}$ into various types of SoA, or evaluation of the pre-clinical affinity biomeasures or functional assays and their translatability to the clinical setting. Not every project needs a site-of-action or a quantitative systems pharmacology model for successful

\section{REFERENCES}

Aarons, L. (2005). Physiologically Based Pharmacokinetic Modelling: a Sound Mechanistic Basis Is Needed. Br. J. Clin. Pharmacol. 60 (6), 581-583. doi:10.1111/j.1365-2125.2005.02560.x

Allerheiligen, S. R. (2010). Next-generation Model-Based Drug Discovery and Development: Quantitative and Systems Pharmacology. Clin. Pharmacol. Ther. 88 (1), 135-137. doi:10.1038/clpt.2010.81

An, B., Zhang, M., Pu, J., Qu, Y., Shen, S., Zhou, S., et al. (2020). Toward Accurate and Robust Liquid Chromatography-Mass Spectrometry-Based Quantification of Antibody Biotherapeutics in Tissues. Anal. Chem. 92 (22), 15152-15161. doi:10.1021/acs.analchem.0c03620

Anaptysbio, I. (2014). Etokimab. Available from: https://www.anaptysbio.com/ pipeline/etokimab/.

Andersen, M. E. (1995). Physiologically Based Pharmacokinetic (PB-PK) Models in the Study of the Disposition and Biological Effects of Xenobiotics and Drugs. Toxicol. Lett. 82-83, 341-348. doi:10.1016/0378-4274(95)03487-0 translation from discovery to development. For the ones where understanding of the underlying pharmacology is limited, a simple exposure-response approach may be sufficient.

\section{CONCLUSION}

Ultimately, the SoA platform model is a useful framework that has allowed us to inform the progression of many successful $\mathrm{mAb}$ programs. In particular, we have used the model to determine the doability of targets, drug requirements for "best in class" mAbs and dosing regimens to achieve required levels of target coverage to demonstrate efficacy. This modeling approach is fully integrated in the drug discovery process with the ability to make decisions believed to be high.

\section{DATA AVAILABILITY STATEMENT}

Publicly available datasets were analyzed in this study. Available data is referenced in the article (literature references only).

\section{AUTHOR CONTRIBUTIONS}

$\mathrm{HJ}$ and GK conceived the concept. GK, JC, JN, and MR conducted the modeling research. HN, JP, VF, and JJ conducted the biomeasures research. RW and HJ supervised the research and manuscript. GK wrote the manuscript with support and contributions from all other authors.

\section{SUPPLEMENTARY MATERIAL}

The Supplementary Material for this article can be found online at: https:/www.frontiersin.org/articles/10.3389/fbinf.2021.731340/ full\#supplementary-material.

Artru, F., Bou Saleh, M., Maggiotto, F., Lassailly, G., Ningarhari, M., Demaret, J., et al. (2020). IL-33/ST2 Pathway Regulates Neutrophil Migration and Predicts Outcome in Patients with Severe Alcoholic Hepatitis. J. Hepatol. 72 (6), 1052-1061. doi:10.1016/j.jhep.2019.12.017

Ashkar, S., Weber, G. F., Panoutsakopoulou, V., Sanchirico, M. E., Jansson, M., Zawaideh, S., et al. (2000). Eta-1 (Osteopontin): an Early Component of Type-1 (Cell-mediated) Immunity. Science 287 (5454), 860-864. doi:10.1126/ science.287.5454.860

Aston, P. J., Derks, G., Raji, A., Agoram, B. M., and van der Graaf, P. H. (2011). Mathematical Analysis of the PharmacokineticPharmacodynamic (PKPD) Behaviour of Monoclonal Antibodies: Predicting In Vivo Potency. J. Theor. Biol. 281 (1), 113-121. doi:10.1016/j.jtbi.2011.04.030

Banks, R. E., Forbes, M. A., Patel, P. M., Storr, M., Hallam, S., Clarke, D., et al. (2000). Subcutaneous Administration of Recombinant Glycosylated Interleukin 6 in Patients with Cancer: Pharmacokinetics, Pharmacodynamics and Immunomodulatory Effects. Cytokine 12 (4), 388-396. doi:10.1006/ cyto. 1999.0556 
Bantscheff, M., Schirle, M., Sweetman, G., Rick, J., and Kuster, B. (2007). Quantitative Mass Spectrometry in Proteomics: a Critical Review. Anal. Bioanal. Chem. 389 (4), 1017-1031. doi:10.1007/s00216-007-1486-6

Barrett, J. S., Fossler, M. J., Cadieu, K. D., and Gastonguay, M. R. (2008). Pharmacometrics: a Multidisciplinary Field to Facilitate Critical Thinking in Drug Development and Translational Research Settings. J. Clin. Pharmacol. 48 (5), 632-649. doi:10.1177/0091270008315318

Barton, H. A., Chiu, W. A., Setzer, R. W., Andersen, M. E., Bailer, A. J., Bois, F. Y., et al. (2007). Characterizing Uncertainty and Variability in Physiologically Based Pharmacokinetic Models: State of the Science and Needs for Research and Implementation. Toxicol. Sci. 99 (2), 395-402. doi:10.1093/toxsci/kfm100

Bateman, R. J., Munsell, L. Y., Morris, J. C., Swarm, R., Yarasheski, K. E., and Holtzman, D. M. (2006). Human Amyloid-Beta Synthesis and Clearance Rates as Measured in Cerebrospinal Fluid In Vivo. Nat. Med. 12 (7), 856-861. doi: $10.1038 / \mathrm{nm} 1438$

Baxter, L. T., Zhu, H., Mackensen, D. G., Butler, W. F., and Jain, R. K. (1995). Biodistribution of Monoclonal Antibodies: Scale-Up from Mouse to Human Using a Physiologically Based Pharmacokinetic Model. Cancer Res. 55 (20), 4611-4622.

Baxter, L. T., Zhu, H., Mackensen, D. G., and Jain, R. K. (1994). Physiologically Based Pharmacokinetic Model for Specific and Nonspecific Monoclonal Antibodies and Fragments in normal Tissues and Human Tumor Xenografts in Nude Mice. Cancer Res. 54 (6), 1517-1528.

Becker, J. O., and Hoofnagle, A. N. (2012). Replacing Immunoassays with Tryptic Digestion-Peptide Immunoaffinity Enrichment and LC-MS/MS. Bioanalysis 4 (3), 281-290. doi:10.4155/bio.11.319

Benson, N., Cucurull-Sanchez, L., Demin, O., Smirnov, S., and van der Graaf, P-H. (2011). Reducing Systems Biology to Practice in Pharmaceutical Company Research; Selected Case Studies. Adv. Exp. Med. Biol., 736, 607-615. doi:10.1007/978-1-4419-7210-1_36

Betts, A., Keunecke, A., van Steeg, T. J., van der Graaf, P. H., Avery, L. B., Jones, H., et al. (2018). Linear Pharmacokinetic Parameters for Monoclonal Antibodies Are Similar within a Species and across Different Pharmacological Targets: A Comparison between Human, Cynomolgus Monkey and hFcRn Tg32 Transgenic Mouse Using a Population-Modeling Approach. MAbs 10, 751-764. doi:10.1080/19420862.2018.1462429

Blakey, G. E., Nestorov, I. A., Arundel, P. A., Aarons, L. J., and Rowland, M. (1997). Quantitative Structure-Pharmacokinetics Relationships: I. Development of a Whole-Body Physiologically Based Model to Characterize Changes in Pharmacokinetics across a Homologous Series of Barbiturates in the Rat. J. Pharmacokinet. Biopharm. 25 (3), 277-312. doi:10.1023/a:1025771608474

Bouma, G., Zamuner, S., Hicks, K., Want, A., Oliveira, J., Choudhury, A., et al. (2017). CCL20 Neutralization by a Monoclonal Antibody in Healthy Subjects Selectively Inhibits Recruitment of CCR6+ Cells in an Experimental Suction Blister. Br. J. Clin. Pharmacol. 83 (9), 1976-1990. doi:10.1111/bcp.13286

Bouzom, F., Ball, K., Perdaems, N., and Walther, B. (2012). Physiologically Based Pharmacokinetic (PBPK) Modelling Tools: How to Fit with Our Needs?. Biopharm. Drug Dispos 33 (2), 55-71. doi:10.1002/bdd.1767

Brodfuehrer, J., Rankin, A., Edmonds, J., Keegan, S., Andreyeva, T., LawrenceHenderson, R., et al. (2014). Quantitative Analysis of Target Coverage and Germinal Center Response by a CXCL13 Neutralizing Antibody in a T-dependent Mouse Immunization Model. Pharm. Res. 31 (3), 635-648. doi:10.1007/s11095-013-1185-2

Cai, H., Stoner, C., Reddy, A., Freiwald, S., Smith, D., Winters, R., et al. (2006). Evaluation of an Integrated In Vitro-In Silico PBPK (Physiologically Based Pharmacokinetic) Model to Provide Estimates of Human Bioavailability. Int. J. Pharm. 308 (1-2), 133-139. doi:10.1016/j.ijpharm.2005.11.002

Chabot, J. R., Dettling, D. E., Jasper, P. J., and Gomes, B. C. (2011). Comprehensive Mechanism-Based Antibody Pharmacokinetic Modeling. Annu. Int. Conf. IEEE Eng. Med. Biol. Soc. 2011, 4318-4323. doi:10.1109/IEMBS.2011.6091072

Chandriani, S., DePianto, D. J., N'Diaye, E. N., Abbas, A. R., Jackman, J., Bevers, J., et al. (2014). Endogenously Expressed IL-13Ra2 Attenuates IL-13-mediated Responses but Does Not Activate Signaling in Human Lung Fibroblasts. J. Immunol. 193 (1), 111-119. doi:10.4049/jimmunol.1301761

Clemente, N., Raineri, D., Cappellano, G., Boggio, E., Favero, F., Soluri, M. F., et al. (2016). Osteopontin Bridging Innate and Adaptive Immunity in Autoimmune Diseases. J. Immunol. Res. 2016, 7675437. doi:10.1155/2016/7675437
Cohen, E. S., Scott, I. C., Majithiya, J. B., Rapley, L., Kemp, B. P., England, E., et al. (2015). Oxidation of the Alarmin IL-33 Regulates ST2-dependent Inflammation. Nat. Commun. 6 (1), 8327. doi:10.1038/ncomms9327

Creaven, P. J., Plager, J. E., Dupere, S., Huben, R. P., Takita, H., Mittelman, A., et al. (1987). Phase I Clinical Trial of Recombinant Human Tumor Necrosis Factor. Cancer Chemother. Pharmacol. 20 (2), 137-144. doi:10.1007/BF00253968

Cucurull-Sanchez, L., Chappell, M. J., Chelliah, V., Amy Cheung, S. Y., Derks, G., Penney, M., et al. (2019). Best Practices to Maximize the Use and Reuse of Quantitative and Systems Pharmacology Models: Recommendations from the United Kingdom Quantitative and Systems Pharmacology Network. CPT Pharmacometrics Syst. Pharmacol. 8 (5), 259-272. doi:10.1002/psp4.12381

Danhof, M., Klein, K., Stolk, P., Aitken, M., and Leufkens, H. (2018). The Future of Drug Development: the Paradigm Shift towards Systems Therapeutics. Drug Discov. Today 23 (12), 1990-1995. doi:10.1016/j.drudis.2018.09.002

De Boever, E. H., Ashman, C., Cahn, A. P., Locantore, N. W., Overend, P., Pouliquen, I. J., et al. (2014). Efficacy and Safety of an anti-IL-13 mAb in Patients with Severe Asthma: a Randomized Trial. J. Allergy Clin. Immunol. 133 (4), 989-996. doi:10.1016/j.jaci.2014.01.002

Derendorf, H., and Meibohm, B. (1999). Modeling of Pharmacokinetic/ Pharmacodynamic (PK/PD) Relationships: Concepts and Perspectives. Pharm. Res. 16 (2), 176-185. doi:10.1023/a:1011907920641

Dirks, N. L., and Meibohm, B. (2010). Population Pharmacokinetics of Therapeutic Monoclonal Antibodies. Clin. Pharmacokinet. 49 (10), 633-659. doi:10.2165/ 11535960-000000000-00000

Doherty, M. K., and Whitfield, P. D. (2011). Proteomics Moves from Expression to Turnover: Update and Future Perspective. Expert Rev. Proteomics 8 (3), 325-334. doi:10.1586/epr.11.19

Edginton, A. N., Theil, F. P., Schmitt, W., and Willmann, S. (2008). Whole Body Physiologically-Based Pharmacokinetic Models: Their Use in Clinical Drug Development. Expert Opin. Drug Metab. Toxicol. 4 (9), 1143-1152. doi:10.1517/ 17425255.4.9.1143

Farrokhi, V., Chabot, J. R., Neubert, H., and Yang, Z. (2018). Assessing the Feasibility of Neutralizing Osteopontin with Various Therapeutic Antibody Modalities. Sci. Rep. 8 (1), 7781. doi:10.1038/s41598-018-26187-w

Farrokhi, V., Chen, X., and Neubert, H. (2018). Protein Turnover Measurements in Human Serum by Serial Immunoaffinity LC-MS/MS. Clin. Chem. 64 (2), 279-288. doi:10.1373/clinchem.2017.272922

Foote, J., and Eisen, H. N. (1995). Kinetic and Affinity Limits on Antibodies Produced during Immune Responses. Proc. Natl. Acad. Sci. U S A. 92 (5), 1254-1256. doi:10.1073/pnas.92.5.1254

Gauvreau, G. M., Boulet, L. P., Cockcroft, D. W., Fitzgerald, J. M., Carlsten, C., Davis, B. E., et al. (2011). Effects of Interleukin-13 Blockade on AllergenInduced Airway Responses in Mild Atopic Asthma. Am. J. Respir. Crit. Care Med. 183 (8), 1007-1014. doi:10.1164/rccm.201008-12100C

Glück, J., Rymarczyk, B., Jura-Szołtys, E., and Rogala, B. (2019). Serum Levels of Interleukin 33 and its Receptor ST2 in Patients Treated with Subcutaneous Allergen Immunotherapy in Intermittent Allergic Rhinitis. Cent. Eur. J. Immunol. 44 (2), 214-217.

Grass, G. M., and Sinko, P. J. (2002). Physiologically-based Pharmacokinetic Simulation Modelling. Adv. Drug Deliv. Rev. 54 (3), 433-451. doi:10.1016/ s0169-409x (02)00013-3

Griesenauer, B., and Paczesny, S. (2017). The ST2/IL-33 Axis in Immune Cells during Inflammatory Diseases. Front. Immunol. 8, 475. doi:10.3389/ fimmu.2017.00475

Grimm, H. P. (2009). Gaining Insights into the Consequences of Target-Mediated Drug Disposition of Monoclonal Antibodies Using Quasi-Steady-State Approximations, J. Pharmacokinet. Pharmacodyn, 36, 1573-8744. doi:10.1007/s10928-009-9129-5

Guttman-Yassky, E., Blauvelt, A., Eichenfield, L. F., Paller, A. S., Armstrong, A. W., Drew, J., et al. (2020). Efficacy and Safety of Lebrikizumab, a High-Affinity Interleukin 13 Inhibitor, in Adults with Moderate to Severe Atopic Dermatitis: A Phase 2b Randomized Clinical Trial. JAMA Dermatol. 156 (4), 411-420. doi:10.1001/jamadermatol.2020.0079

Hanania, N. A., Korenblat, P., Chapman, K. R., Bateman, E. D., Kopecky, P., Paggiaro, P., et al. (2016). Efficacy and Safety of Lebrikizumab in Patients with Uncontrolled Asthma (LAVOLTA I and LAVOLTA II): Replicate, Phase 3, Randomised, Double-Blind, Placebo-Controlled Trials. Lancet Respir. Med. 4 (10), 781-796. doi:10.1016/S2213-2600(16)30265-X 
Hinkson, I. V., and Elias, J. E. (2011). The Dynamic State of Protein Turnover: It's about Time. Trends Cel Biol. 21 (5), 293-303. doi:10.1016/ j.tcb.2011.02.002

Hoang, K. (1995). Physiologically Based Pharmacokinetic Models: Mathematical Fundamentals and Simulation Implementations. Toxicol. Lett. 79 (1-3), 99-106. doi:10.1016/0378-4274(95)03361-n

Hopkins, A. L. (2008). Network Pharmacology: the Next Paradigm in Drug Discovery. Nat. Chem. Biol. 4 (11), 682-690. doi:10.1038/nchembio.118

Huang, S. M., and Rowland, M. (2012). The Role of Physiologically Based Pharmacokinetic Modeling in Regulatory Review. Clin. Pharmacol. Ther. 91 (3), 542-549. doi:10.1038/clpt.2011.320

Jacobs, C. A., Beckmann, M. P., Mohler, K., Maliszewski, C. R., Fanslow, W. C., and Lynch, D. H. (1993). Pharmacokinetic Parameters and Biodistribution of Soluble Cytokine Receptors. Int. Rev. Exp. Pathol. 34 Pt B, 123-135. doi:10.1016/b978-0-12-364935-5.50013-4

Janeway, C. A., Jr, and Walport, M. (2001). Immunobiology: The Immune System in Health and Disease. 5th ed. New York: Garland Science.

Jones, H. M., Barton, H. A., Lai, Y., Bi, Y. A., Kimoto, E., Kempshall, S., et al. (2012). Mechanistic Pharmacokinetic Modeling for the Prediction of Transporter-Mediated Disposition in Humans from sandwich Culture Human Hepatocyte Data. Drug Metab. Dispos 40 (5), 1007-1017. doi:10.1124/dmd.111.042994

Jones, H. M., Dickins, M., Youdim, K., Gosset, J. R., Attkins, N. J., Hay, T. L., et al. (2012). Application of PBPK Modelling in Drug Discovery and Development at Pfizer. Xenobiotica 42 (1), 94-106. doi:10.3109/ 00498254.2011.627477

Jones, H. M., Gardner, I. B., Collard, W. T., Stanley, P. J., Oxley, P., Hosea, N. A., et al. (2011). Simulation of Human Intravenous and Oral Pharmacokinetics of 21 Diverse Compounds Using Physiologically Based Pharmacokinetic Modelling. Clin. Pharmacokinet. 50 (5), 331-347. doi:10.2165/11539680000000000-00000

Jones, H. M., Gardner, I. B., and Watson, K. J. (2009). Modelling and PBPK Simulation in Drug Discovery. AAPS J. 11 (1), 155-166. doi:10.1208/s12248-009-9088-1

Jones, H. M., Mayawala, K., and Poulin, P. (2013). Dose Selection Based on Physiologically Based Pharmacokinetic (PBPK) Approaches. AAPS J. 15 (2), 377-387. doi:10.1208/s12248-012-9446-2

Jones, H. M., Parrott, N., Jorga, K., and Lavé, T. (2006). A Novel Strategy for Physiologically Based Predictions of Human Pharmacokinetics. Clin. Pharmacokinet. 45 (5), 511-542. doi:10.2165/00003088-200645050-00006

Jones, H. M., Parrott, N., Ohlenbusch, G., and Lavé, T. (2006). Predicting Pharmacokinetic Food Effects Using Biorelevant Solubility media and Physiologically Based Modelling. Clin. Pharmacokinet. 45 (12), 1213-1226. doi:10.2165/00003088-200645120-00006

Jones, H. M., Tolsma, J., Zhang, Z., Jasper, P., Luo, H., Weber, G. L., et al. (2020). A Physiologically-Based Pharmacokinetic Model for the Prediction of "HalfLife Extension" and "Catch and Release" Monoclonal Antibody Pharmacokinetics. CPT Pharmacometrics Syst. Pharmacol. 9 (9), 534-541. doi:10.1002/psp4.12547

Jones, H. M., Zhang, Z., Jasper, P., Luo, H., Avery, L. B., King, L. E., et al. (2019). A Physiologically-Based Pharmacokinetic Model for the Prediction of Monoclonal Antibody Pharmacokinetics from In Vitro Data. CPT Pharmacometrics Syst. Pharmacol. 8 (10), 738-747. doi:10.1002/ psp4.12461

Jusko, W. J. (2013). Moving from Basic toward Systems Pharmacodynamic Models. J. Pharm. Sci. 102 (9), 2930-2940. doi:10.1002/jps.23590

Kasaian, M. T., Raible, D., Marquette, K., Cook, T. A., Zhou, S., Tan, X. Y., et al. (2011). IL-13 Antibodies Influence IL-13 Clearance in Humans by Modulating Scavenger Activity of IL-13Ra2. J. Immunol. 187 (1), 561-569. doi:10.4049/ jimmunol.1100467

Khodoun, M., Lewis, C. C., Lewis, C., Yang, J. Q., Orekov, T., Potter, C., et al. (2007). Differences in Expression, Affinity, and Function of Soluble (s)IL4Ralpha and sIL-13Ralpha2 Suggest Opposite Effects on Allergic Responses. J. Immunol. 179 (10), 6429-6438. doi:10.4049/ jimmunol.179.10.6429

Kitano, H. (2005). International Alliances for Quantitative Modeling in Systems Biology. Mol. Syst. Biol. 1, 2005-0007. doi:10.1038/msb4100011

Knight-Schrijver, V. R., Chelliah, V., Cucurull-Sanchez, L., and Le Novère, N. (2016). The Promises of Quantitative Systems Pharmacology Modelling for
Drug Development. Comput. Struct. Biotechnol. J. 14, 363-370. doi:10.1016/ j.csbj.2016.09.002

Kohl, P., Crampin, E. J., Quinn, T. A., and Noble, D. (2010). Systems Biology: an Approach. Clin. Pharmacol. Ther. 88 (1), 25-33. doi:10.1038/clpt.2010.92

Kroegel, C., Julius, P., Matthys, H., Virchow, J. C., and Luttmann, W. (1996). Endobronchial Secretion of Interleukin-13 Following Local Allergen challenge in Atopic Asthma: Relationship to Interleukin-4 and Eosinophil Counts. Eur. Respir. J. 9 (5), 899-904. doi:10.1183/09031936.96.09050899

Lalonde, R. L., Kowalski, K. G., Hutmacher, M. M., Ewy, W., Nichols, D. J., Milligan, P. A., et al. (2007). Model-based Drug Development. Clin. Pharmacol. Ther. 82 (1), 21-32. doi:10.1038/sj.clpt.6100235

Larance, M., and Lamond, A. I. (2015). Multidimensional Proteomics for Cell Biology. Nat. Rev. Mol. Cel Biol. 16, 269-280. doi:10.1038/nrm3970

Lassman, M. E., McAvoy, T., Lee, A. Y., Chappell, D., Wong, O., Zhou, H., et al. (2014). Practical Immunoaffinity-Enrichment LC-MS for Measuring Protein Kinetics of Low-Abundance Proteins. Clin. Chem. 60 (9), 1217-1224. doi:10.1373/clinchem.2014.222455

Leo Pharma announces European Commission Approval of Adtralza ${ }^{\circledR}$ (Tralokinumab) as the First and Only Treatment Specifically Targeting IL-13 for Adults with Moderate-To-Severe Atopic Dermatitis [press release]. 2021.

Li, Z., Krippendorff, B. F., and Shah, D. K. (2017). Influence of Molecular Size on the Clearance of Antibody Fragments. Pharm. Res. 34 (10), 2131-2141. doi:10.1007/s11095-017-2219-y

Lindwall, G., Hsieh, E. A., Misell, L. M., Chai, C. M., Turner, S. M., and Hellerstein, M. K. (2006). Heavy Water Labeling of Keratin as a Non-invasive Biomarker of Skin Turnover In Vivo in Rodents and Humans. J. Invest. Dermatol. 126 (4), 841-848. doi:10.1038/sj.jid.5700189

Liu, Y., Cao, L., Chen, R., Zhou, X., Fan, X., Liang, Y., et al. (2015). Osteopontin Promotes Hepatic Progenitor Cell Expansion and Tumorigenicity via Activation of $\beta$-Catenin in Mice. Stem Cells 33 (12), 3569-3580. doi:10.1002/stem.2072

Loizou, G., Spendiff, M., Barton, H. A., Bessems, J., Bois, F. Y., d'Yvoire, M. B., et al. (2008). Development of Good Modelling Practice for Physiologically Based Pharmacokinetic Models for Use in Risk Assessment: the First Steps. Regul. Toxicol. Pharmacol. 50 (3), 400-411. doi:10.1016/ j.yrtph.2008.01.011

Lund, S. A., Wilson, C. L., Raines, E. W., Tang, J., Giachelli, C. M., and Scatena, M. (2013). Osteopontin Mediates Macrophage Chemotaxis via $\alpha 4$ and $\alpha 9$ Integrins and Survival via the a4 Integrin. J. Cel Biochem. 114 (5), 1194-1202. doi:10.1002/jcb.24462

Mager, D. E., and Jusko, W. J. (2008). Development of Translational Pharmacokinetic-Pharmacodynamic Models. Clin. Pharmacol. Ther. 83 (6), 909-912. doi:10.1038/clpt.2008.52

May, R. D., and Fung, M. (2015). Strategies Targeting the IL-4/IL-13 Axes in Disease. Cytokine 75 (1), 89-116. doi:10.1016/j.cyto.2015.05.018

McAvoy, T., Lassman, M. E., Spellman, D. S., Ke, Z., Howell, B. J., Wong, O., et al. (2014). Quantification of Tau in Cerebrospinal Fluid by Immunoaffinity Enrichment and Tandem Mass Spectrometry. Clin. Chem. 60 (4), 683-689. doi:10.1373/clinchem.2013.216515

Meibohm, B., and Derendorf, H. (1997). Basic Concepts of Pharmacokinetic/ pharmacodynamic (PK/PD) Modelling. Int. J. Clin. Pharmacol. Ther. 35 (10), 401-413.

Mueller, T., and Dieplinger, B. (2016). Soluble ST2 and Galectin-3: What We Know and Don't Know Analytically. EJIFCC 27 (3), 224-237.

Nestorov, I. (2007). Whole-body Physiologically Based Pharmacokinetic Models. Expert Opin. Drug Metab. Toxicol. 3 (2), 235-249. doi:10.1517/ 17425255.3.2.235

Nestorov, I. A., Aarons, L. J., Arundel, P. A., and Rowland, M. (1998). Lumping of Whole-Body Physiologically Based Pharmacokinetic Models. J. Pharmacokinet. Biopharm. 26 (1), 21-46. doi:10.1023/a:1023272707390

Neubert, H., Muirhead, D., Kabir, M., Grace, C., Cleton, A., and Arends, R. (2013). Sequential Protein and Peptide Immunoaffinity Capture for Mass Spectrometry-Based Quantification of Total Human $\beta$-nerve Growth Factor. Anal. Chem. 85 (3), 1719-1726. doi:10.1021/ac303031q

Neubert, H., Shuford, C. M., Olah, T. V., Garofolo, F., Schultz, G. A., Jones, B. R., et al. (2020). Protein Biomarker Quantification by Immunoaffinity Liquid Chromatography-Tandem Mass Spectrometry: Current State and 
Future Vision. Clin. Chem. 66 (2), 282-301. doi:10.1093/clinchem/ hvz022

Nijsen, M. J. M. A., Wu, F., Bansal, L., Bradshaw-Pierce, E., Chan, J. R., Liederer, B. M., et al. (2018). Preclinical QSP Modeling in the Pharmaceutical Industry: An IQ Consortium Survey Examining the Current Landscape. CPT Pharmacometrics Syst. Pharmacol. 7 (3), 135-146. doi:10.1002/psp4.12282

Noonan, M., Korenblat, P., Mosesova, S., Scheerens, H., Arron, J. R., Zheng, Y., et al. (2013). Dose-ranging Study of Lebrikizumab in Asthmatic Patients Not Receiving Inhaled Steroids. J. Allergy Clin. Immunol. 132 (3), 567-e12. doi:10.1016/j.jaci.2013.03.051

Norris, D. A., Leesman, G. D., Sinko, P. J., and Grass, G. M. (2000). Development of Predictive Pharmacokinetic Simulation Models for Drug Discovery. J. Control. Release 65 (1-2), 55-62. doi:10.1016/s0168-3659(99)00232-1

Oshikawa, K., Kuroiwa, K., Tago, K., Iwahana, H., Yanagisawa, K., Ohno, S., et al. (2001). Elevated Soluble ST2 Protein Levels in Sera of Patients with Asthma with an Acute Exacerbation. Am. J. Respir. Crit. Care Med. 164 (2), 277-281. doi:10.1164/ajrccm.164.2.2008120

Owen, S. G., Francis, H. W., and Roberts, M. S. (1994). Disappearance Kinetics of Solutes from Synovial Fluid after Intra-articular Injection. Br. J. Clin. Pharmacol. 38 (4), 349-355. doi:10.1111/j.1365-2125.1994.tb04365.x

Palandra, J., Finelli, A., Zhu, M., Masferrer, J., and Neubert, H. (2013). Highly Specific and Sensitive Measurements of Human and Monkey Interleukin 21 Using Sequential Protein and Tryptic Peptide Immunoaffinity LC-MS/MS. Anal. Chem. 85 (11), 5522-5529. doi:10.1021/ac4006765

Palandra, J., Quazi, A., Fitz, L., Rong, H., Morris, C., and Neubert, H. (2016). Quantitative Measurements of GDF-8 Using Immunoaffinity LC-MS/MS. Proteomics Clin. Appl. 10 (5), 597-604. doi:10.1002/prca.201500112

Palmer, G., Lipsky, B. P., Smithgall, M. D., Meininger, D., Siu, S., Talabot-Ayer, D., et al. (2008). The IL-1 Receptor Accessory Protein (AcP) Is Required for IL-33 Signaling and Soluble AcP Enhances the Ability of Soluble ST2 to Inhibit IL-33. Cytokine 42 (3), 358-364. doi:10.1016/j.cyto.2008.03.008

Peterson, M. C., and Riggs, M. M. (2015). FDA Advisory Meeting Clinical Pharmacology Review Utilizes a Quantitative Systems Pharmacology (QSP) Model: A Watershed Moment?. CPT Pharmacometrics Syst. Pharmacol. 4 (3), e00020-92. doi:10.1002/psp4.20

A Multi-Compartmental Model Generally Applicable to Physiologically-Based Pharmacokinetics,"P. H. Arundel in 3rd IFAC Symposium; Modelling and Control in Biomedial Systems (UK: University of Warwick).

Popovic, B., Breed, J., Rees, D. G., Gardener, M. J., Vinall, L. M., Kemp, B., et al. (2017). Structural Characterisation Reveals Mechanism of IL-13-Neutralising Monoclonal Antibody Tralokinumab as Inhibition of Binding to IL-13Ra1 and IL-13Ra2. J. Mol. Biol. 429 (2), 208-219. doi:10.1016/j.jmb.2016.12.005

Poulin, P., and Theil, F. P. (2002). Prediction of Pharmacokinetics Prior to In Vivo Studies. 1. Mechanism-Based Prediction of Volume of Distribution. J. Pharm. Sci. 91 (1), 129-156. doi:10.1002/jps.10005

Rajman, I. (2008). PK/PD Modelling and Simulations: Utility in Drug Development. Drug Discov. Today 13 (7), 341-346. doi:10.1016/j.drudis.2008.01.003

Regeneron Pharmaceuticals, I. (2019). Regeneron and Sanofi Announce Positive Topline Phase 2 Results for IL-33 Antibody in Asthma June 21, 2019. Available from: https://investor.regeneron.com/news-releases/news-release-details/ regeneron-and-sanofi-announce-positive-topline-phase-2-results/ (Acessed on June 21, 2019)

Rogers, M., Lyster, P., and Okita, R. (2013). NIH Support for the Emergence of Quantitative and Systems Pharmacology. CPT: Pharmacometrics Syst. Pharmacol. 2 (4), 37. doi:10.1038/psp.2013.13

Rostami-Hodjegan, A., Tamai, I., and Pang, K. S. (2012). Physiologically Based Pharmacokinetic (PBPK) Modeling: it Is Here to Stay!. Biopharm. Drug Dispos 33 (2), 47-50. doi:10.1002/bdd.1776

Saluja, R., Khan, M., Church, M. K., and Maurer, M. (2015). The Role of IL-33 and Mast Cells in Allergy and Inflammation. Clin. Transl Allergy 5 (1), 33. doi:10.1186/s13601-015-0076-5

Saluja, R., Zoltowska, A., Ketelaar, M. E., and Nilsson, G. (2016). IL-33 and Thymic Stromal Lymphopoietin in Mast Cell Functions. Eur. J. Pharmacol. 778, 68-76. doi:10.1016/j.ejphar.2015.04.047

Schutyser, E., Struyf, S., and Van Damme, J. (2003). The CC Chemokine CCL20 and its Receptor CCR6. Cytokine Growth Factor. Rev. 14 (5), 409-426. doi:10.1016/s1359-6101(03)00049-2
Scott, I. C., Majithiya, J. B., Sanden, C., Thornton, P., Sanders, P. N., Moore, T., et al. (2018). Interleukin-33 Is Activated by Allergen- and Necrosis-Associated Proteolytic Activities to Regulate its Alarmin Activity during Epithelial Damage. Sci. Rep. 8 (1), 3363. doi:10.1038/s41598-018-21589-2

Shah, D. K., and Betts, A. M. (2013). Antibody Biodistribution Coefficients: Inferring Tissue Concentrations of Monoclonal Antibodies Based on the Plasma Concentrations in Several Preclinical Species and Human. MAbs 5 (2), 297-305. doi:10.4161/mabs.23684

Shah, D. K., and Betts, A. M. (2012). Towards a Platform PBPK Model to Characterize the Plasma and Tissue Disposition of Monoclonal Antibodies in Preclinical Species and Human. J. Pharmacokinet. Pharmacodyn 39 (1), 67-86. doi:10.1007/s10928-011-9232-2

Shuford, C. M., Johnson, J. S., Thompson, J. W., Holland, P. L., Hoofnagle, A. N., and Grant, R. P. (2020). More Sensitivity Is Always Better: Measuring Subclinical Levels of Serum Thyroglobulin on a $\mu$ LC-MS/MS System. Clin. Mass Spectrom. 15, 29-35. doi:10.1016/j.clinms.2020.01.001

Tang, Y., Zeng, X., and Liang, J. (2010). Surface Plasmon Resonance: An Introduction to a Surface Spectroscopy Technique. J. Chem. Educ. 87 (7), 742-746. doi:10.1021/ed100186y

Tiwari, A., Abraham, A. K., Harrold, J. M., Zutshi, A., and Singh, P. (2017). Optimal Affinity of a Monoclonal Antibody: Guiding Principles Using Mechanistic Modeling, AAPS J., 19, 1550-7416. doi:10.1208/s12248-0160004-1

Tiwari, A., Kasaian, M., Heatherington, A. C., Jones, H. M., and Hua, F. (2016). A Mechanistic PK/PD Model for Two anti-IL13 Antibodies Explains the Difference in Total IL-13 Accumulation Observed in Clinical Studies. MAbs 8 (5), 983-990. doi:10.1080/19420862.2016.1172151

Tiwari, A., Luo, H., Chen, X., Singh, P., Bhattacharya, I., Jasper, P., et al. (2016). Assessing the Impact of Tissue Target Concentration Data on Uncertainty in In Vivo Target Coverage Predictions. CPT Pharmacometrics Syst. Pharmacol. 5 (10), 565-574. doi:10.1002/psp4.12126

Ultsch, M., Bevers, J., Nakamura, G., Vandlen, R., Kelley, R. F., Wu, L. C., et al. (2013). Structural Basis of Signaling Blockade by Anti-IL-13 Antibody Lebrikizumab. J. Mol. Biol. 425 (8), 1330-1339. doi:10.1016/ j.jmb.2013.01.024

van der Graaf, P. H., and Benson, N. (2011). Systems Pharmacology: Bridging Systems Biology and Pharmacokinetics-Pharmacodynamics (PKPD) in Drug Discovery and Development. Pharm. Res. 28 (7), 1460-1464. doi:10.1007/ s11095-011-0467-9

van der Graaf, P. H. (2012). CPT: Pharmacometrics and Systems Pharmacology. CPT Pharmacometrics Syst. Pharmacol. 1 (9), e8-e. doi: $10.1038 /$ psp. 2012.8

van Hartingsveldt, B., Nnane, I. P., Bouman-Thio, E., Loza, M. J., Piantone, A., Davis, H. M., et al. (2013). Safety, Tolerability and Pharmacokinetics of a Human Anti-interleukin-13 Monoclonal Antibody (CNTO 5825) in an Ascending Single-Dose First-In-Human Study. Br. J. Clin. Pharmacol. 75 (5), 1289-1298. doi:10.1111/j.1365-2125.2012.04477.x

Vugmeyster, Y., DeFranco, D., Szklut, P., Wang, Q., and Xu, X. (2010). Biodistribution of [125I]-Labeled Therapeutic Proteins: Application in Protein Drug Development beyond Oncology. J. Pharm. Sci. 99 (2), 1028-1045. doi:10.1002/jps.21855

Vugmeyster, Y., Szklut, P., Tchistiakova, L., Abraham, W., Kasaian, M., and Xu, X. (2008). Preclinical Pharmacokinetics, Interspecies Scaling, and Tissue Distribution of Humanized Monoclonal anti-IL-13 Antibodies with Different IL-13 Neutralization Mechanisms. Int. Immunopharmacol 8 (3), 477-483. doi:10.1016/j.intimp.2007.12.004

Wang, X., Lopategi, A., Ge, X., Lu, Y., Kitamura, N., Urtasun, R., et al. (2014). Osteopontin Induces Ductular Reaction Contributing to Liver Fibrosis. Gut 63 (11), 1805-1818. doi:10.1136/gutjnl-2013-306373

Wani, T. A., Zargar, S., Wakil, S. M., and Darwish, I. A. (2016). New Analytical Application of Antibody-Based Biosensor in Estimation of ThyroidStimulating Hormone in Serum. Bioanalysis 8 (7), 625-632. doi:10.4155/bio2015-0034

Zhang, T. T., Ma, J., Durbin, K. R., Montavon, T., Lacy, S. E., Jenkins, G. J., et al. (2019). Determination of IL-23 Pharmacokinetics by Highly Sensitive Accelerator Mass Spectrometry and Subsequent Modeling to Project IL-23 Suppression in Psoriasis Patients Treated with Anti-IL-23 Antibodies. AAPS J. 21 (5), 82. doi:10.1208/s12248-019-0352-8 
Zhao, P., Rowland, M., and Huang, S. M. (2012). Best Practice in the Use of Physiologically Based Pharmacokinetic Modeling and Simulation to Address Clinical Pharmacology Regulatory Questions. Clin. Pharmacol. Ther. 92 (1), 17-20. doi:10.1038/clpt.2012.68

Zhao, P., Zhang, L., Grillo, J. A., Liu, Q., Bullock, J. M., Moon, Y. J., et al. (2011). Applications of Physiologically Based Pharmacokinetic (PBPK) Modeling and Simulation during Regulatory Review. Clin. Pharmacol. Ther. 89 (2), 259-267. doi:10.1038/clpt.2010.298

Zhao, Y., Liu, G., Kwok, S., Jones, B. R., Liu, J., Marchisin, D., et al. (2018). Highly Selective and Sensitive Measurement of Active Forms of FGF21 Using Novel Immunocapture Enrichment with LC-MS/MS. Bioanalysis 10 (1), 23-33. doi:10.4155/bio-2017-0208

Conflict of Interest: All authors are current or former employees of Pfizer Inc.
Publisher's Note: All claims expressed in this article are solely those of the authors and do not necessarily represent those of their affiliated organizations, or those of the publisher, the editors and the reviewers. Any product that may be evaluated in this article, or claim that may be made by its manufacturer, is not guaranteed or endorsed by the publisher.

Copyright (c) 2021 Kapitanov, Chabot, Narula, Roy, Neubert, Palandra, Farrokhi, Johnson, Webster and Jones. This is an open-access article distributed under the terms of the Creative Commons Attribution License (CC BY). The use, distribution or reproduction in other forums is permitted, provided the original author(s) and the copyright owner(s) are credited and that the original publication in this journal is cited, in accordance with accepted academic practice. No use, distribution or reproduction is permitted which does not comply with these terms. 